\title{
Exploring the effect of antenatal depression treatment on children's epigenetic profiles: findings from a pilot randomized controlled trial
}

Laura S. Bleker ${ }^{1,2^{*}}$, Jeannette Milgrom ${ }^{3,4}$, Alexandra Sexton-Oates ${ }^{5}$, Tessa J. Roseboom,2, Alan W. Gemmill ${ }^{3}$, Christopher J. Holt ${ }^{3}$, Richard Saffery ${ }^{5}$, Huibert Burger ${ }^{6}$ and Susanne R. de Rooij ${ }^{2}$

\begin{abstract}
Background: Children prenatally exposed to maternal depression more often show behavioral and emotional problems compared to unexposed children, possibly through epigenetic alterations. Current evidence is largely based on animal and observational human studies. Therefore, evidence from experimental human studies is needed. In this follow-up of a small randomized controlled trial (RCT), DNA-methylation was compared between children of women who had received cognitive behavioral therapy (CBT) for antenatal depression and children of women who had received treatment as usual (TAU). Originally, 54 women were allocated to CBT or TAU. A beneficial treatment effect was found on women's mood symptoms.
\end{abstract}

Findings: We describe DNA methylation findings in buccal swab DNA of the 3-7-year-old children $(C B T(N)=12, \operatorname{TAU}(\mathrm{N})=11)$ , at a genome-wide level at 770,668 CpG sites and at 729 CpG sites spanning 16 a priori selected candidate genes, including the glucocorticoid receptor (NR3C1). We additionally explored associations with women's baseline depression and anxiety symptoms and offspring DNA methylation, regardless of treatment. Children from the CBT group had overall lower DNA methylation compared to children from the TAU group (mean $\Delta \beta=-0.028,95 \% \mathrm{Cl}-0$. 035 to -0.022 ). Although $68 \%$ of the promoter-associated NR3C1 probes were less methylated in the CBT group, with cg26464411 as top most differentially methylated CpG site $(p=0.038)$, mean DNA methylation of all NR3C1 promoterassociated probes did not differ significantly between the CBT and TAU groups (mean $\triangle \beta=0.002,95 \% \mathrm{Cl}-0.010$ to 0 . 011). None of the effects survived correction for multiple testing. There were no differences in mean DNA methylation between the children born to women with more severe depression or anxiety compared to children born to women with mild symptoms of depression or anxiety at baseline (mean $\Delta \beta$ (depression) $=0.0008,95 \% \mathrm{Cl}-0.007$ to 0.008 ; mean $\Delta \beta$ (anxiety) $=0.0002,95 \% \mathrm{Cl}-0.004$ to 0.005 ).

Conclusion: We found preliminary evidence of a possible effect of CBT during pregnancy on widespread methylation in children's genomes and a trend toward lower methylation of a CpG site previously shown by others to be linked to depression and child maltreatment. However, none of the effects survived correction for multiple testing and larger studies are warranted.

Trial registration: Trial registration of the original RCT: ACTRN12607000397415. Registered on 2 August 2007.

Keywords: DNA methylation, Epigenetics, Neurodevelopment, Antenatal depression, CBT, Programming

\footnotetext{
* Correspondence: I.s.bleker@amc.uva.nl

'Department of Obstetrics and Gynecology, Amsterdam UMC, location AMC, Meibergdreef 9, Amsterdam 1105 AZ, The Netherlands

${ }^{2}$ Department of Clinical Epidemiology, Biostatistics and Bioinformatics,

Amsterdam UMC, location AMC, Meibergdreef 9, Amsterdam 1105 AZ, The

Netherlands

Full list of author information is available at the end of the article
}

(c) The Author(s). 2019 Open Access This article is distributed under the terms of the Creative Commons Attribution 4.0 International License (http://creativecommons.org/licenses/by/4.0/), which permits unrestricted use, distribution, and reproduction in any medium, provided you give appropriate credit to the original author(s) and the source, provide a link to the Creative Commons license, and indicate if changes were made. The Creative Commons Public Domain Dedication waiver (http://creativecommons.org/publicdomain/zero/1.0/) applies to the data made available in this article, unless otherwise stated. 


\section{Background}

Many pregnant women experience clinically significant depressive symptoms before delivery, with an estimated prevalence of 7.4 to $12.8 \%$ [1]. Mounting evidence demonstrates that children prenatally exposed to maternal depression more often have a difficult temperament [2], are more prone to develop internalizing and externalizing behavioral problems [3-7], show poorer performance on cognitive tasks [8, 9], and more often develop depression and anxiety symptoms themselves in (pre)adolescence [10-12]. One mechanism by which antenatal depression might influence susceptibility for psychopathology is by epigenetic regulation of gene expression $[13,14]$. Epigenetic mechanisms regulate the activity of DNA and include post-translational histone modification, micro-RNAs, and DNA methylation [15]. In contrast to the fixed genotype, the epigenome has shown to be highly variable early in development under the influence of environmental factors $[16,17]$.

Animal studies have provided evidence that antenatal stress alters methylation of offspring genes involved in neurodevelopment and is associated with behavioral changes. For example, exposure to chronic stress in early gestation in mice resulted in a stress-sensitive phenotype in male offspring, showing increased immobility in the tail suspension and forced swim test and heightened hypothalamic pituitary adrenal (HPA) axis responsivity, which was accompanied by increased DNA methylation and decreased gene expression of the glucocorticoid receptor in the hippocampus and amygdala [18]. Moreover, alterations in epigenetic profiles have been shown to remain stable across generations, passing on susceptibility for emotional and behavioral disorders from one generation to the next [19].

Since 2008, many human studies have investigated associations between prenatal stress exposure and offspring gene methylation, with a special focus on NR3C1, coding for the glucocorticoid receptor [20]. While the reported effect sizes are usually small, increased methylation status of NR3C1 has been linked to an increased HPA axis stress-response [21]. All studies to date are, however, observational and therefore susceptible to confounding by factors that are both associated with antenatal stress and with methylation patterns, such as maternal smoking during pregnancy [22]. Experimental designs including follow-up of children are currently scarce and urgently needed to establish causality between intrauterine exposures and later life outcomes [23].

The current study investigated effects of maternal depression treatment during pregnancy on DNA methylation profiles in the children. In the Beating the Blues before Birth (BBB) study, pregnant women with a confirmed Diagnostic and Statistical Manual of Mental Disorders, 4th Edition (DSM-IV) depressive disorder were randomized to either the intervention group, consisting of eight cognitive behavioral therapy
(CBT) sessions, or to a control group, consisting of treatment as usual (TAU), which comprised case-managing by a midwife or referral to a general practitioner. Beneficial treatment effects favoring the intervention were found on maternal depression and anxiety. Anxiety symptoms significantly decreased, and depressive symptoms showed a decreasing trend nearly reaching significance, in the intervention versus the control group [24].

We hypothesized that compared to the control group, the intervention would be associated with a change in DNA methylation profiles of buccal swab DNA from the children, (1) at an epigenome-wide level, (2) at 16 a priori selected candidate genes, and (3) at promoter-associated glucocorticoid receptor $(N R 3 C 1)$ probes. We additionally explored whether severity of maternal symptoms of depression and anxiety at baseline would be associated with DNA methylation profiles in the children, regardless of treatment.

\section{Results}

\section{Study sample characteristics}

Of the original study group of 54 women, 2 women had moved overseas to unknown addresses, and 10 women could not be traced. This resulted in 42 women being invited to participate in the current study. In total, 19 women declined to participate. Reasons for declining were lack of time, a lack of interest in being involved, or not wanting their child's DNA to be used for study purposes. This resulted in a study group of 23 women and their children who agreed to participate in the current study, 12 (42.9\%) women from the intervention group and 11 (42.3\%) women from the control group (flowchart; Fig. 1). Table 1 shows baseline characteristics of all women from the original study, women that did not participate, and women that did participate in the current follow-up. In the intervention and control group alike, women that responded to the current follow-up had lower Beck Depression Inventory (BDI-II) and lower Beck Anxiety Inventory (BAI) scores, less often reported using antidepressants, and were more highly educated with a higher annual income compared to non-responders at baseline. In the intervention group, participating women were more often born in Australia and married compared to women who did not participate, whereas in the control group, women were less often born in Australia and married compared to non-responders. Current demographics of the women and their children are shown in Table 2. Less women from the intervention group were currently using an antidepressant, their income was higher, and they more often drank one or more alcoholic unit per week, as compared to the control group.

\section{Association between genome-wide DNA methylation and allocation}

Linear regression analysis was used to identify specific differentially methylated probes according to allocation. 


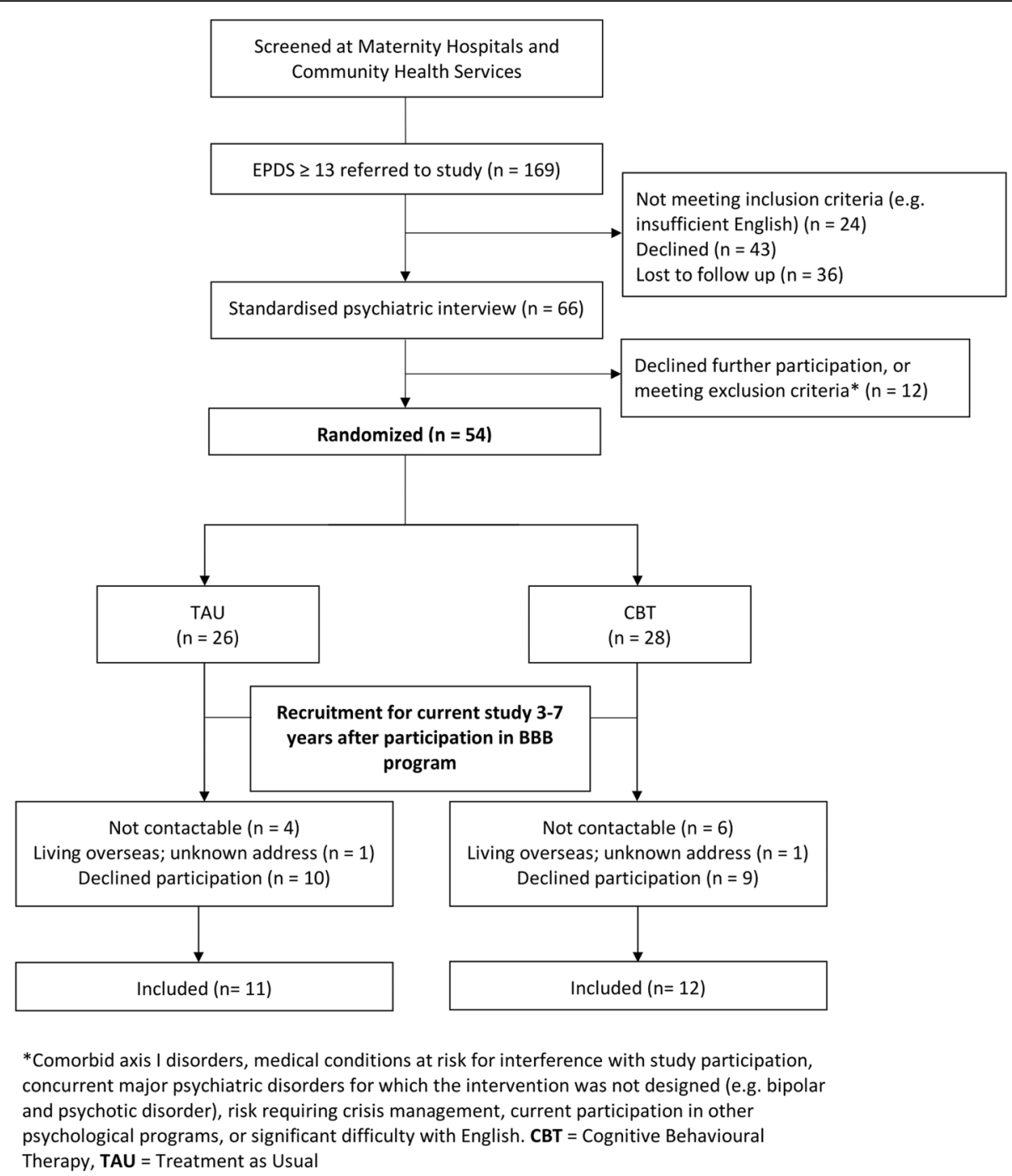

Fig. 1 Flow diagram of participant recruitment. *Comorbid axis I disorders, medical conditions at risk for interference with study participation, concurrent major psychiatric disorders for which the intervention was not designed (e.g., bipolar and psychotic disorder), risk requiring crisis management, current participation in other psychological programs, or significant difficulty with English. CBT cognitive behavioral therapy, TAU treatment as usual

This took into account variation associated with the following covariates: birth weight, HM850 array chip position, sex and age, as identified by principal component analysis (PCA). Linear regression analysis revealed a total of 4780 differentially methylated probes at a nominal significance level $(p<0.01$, uncorrected for multiple testing) between the intervention and the control group, showing higher DNA methylation in the control group (mean $\Delta \beta=-0.028,95 \% \mathrm{CI}-0.035$ to $0.022, p<0.001$ ). Adding current income as an additional covariate did not significantly alter the results (mean $\Delta \beta=$ $-0.026,95 \% \mathrm{CI}-0.031$ to $-0.021, p<0.001$ ). The top 100 differentially methylated probes are presented in Table 3 of the Appendix. Table 4 shows the ten most differentially methylated probes. Of the top five differentially methylated probes, three probes with annotated genes were probe cg15495292 on the AIG1 gene (uncorrected $p=4.01 \mathrm{E}-06$, corrected $p=0.999), \operatorname{cg} 05155812$ on the SUN1 gene (uncorrected $p=1.56 \mathrm{E}-05$, corrected $p=0.999$ ), and cg18818484 on the PTCHD2 gene (uncorrected $p=2.20 \mathrm{E}-05$, corrected $p=0.999)$. After correcting for multiple testing (corrected $p \leq 0.01$ ), no probes remained significantly associated with the intervention.

\section{Candidate gene-specific DNA methylation and allocation}

In addition to an exploratory genome-wide analysis (above), we also tested for associations with a list of a priori chosen candidate genes. Table 5 shows the results of the unpaired Mann-Whitney-Wilcoxon tests, comparing mean DNA methylation of 16 candidate genes between the intervention and control group. No genes were significantly differentially methylated at a nominal 
Table 1 Baseline characteristics of all participants in a trial evaluating an antenatal cognitive behavioral therapy (CBT) versus treatment as usual (TAU), those that responded, and those that did not respond to the 5-year follow-up

\begin{tabular}{|c|c|c|c|c|c|c|}
\hline \multirow[b]{2}{*}{ Baseline demographics } & \multicolumn{2}{|c|}{ All participants } & \multicolumn{2}{|c|}{$\begin{array}{l}\text { Not participating in 5-year } \\
\text { follow-up }\end{array}$} & \multicolumn{2}{|c|}{$\begin{array}{l}\text { Participating in 5-year } \\
\text { follow-up }\end{array}$} \\
\hline & CBT $(n=28)$ & TAU $(n=26)$ & $\overline{C B T}(n=16)$ & TAU $(n=15)$ & CBT $(n=12)$ & $\operatorname{TAU}(n=11)$ \\
\hline Mean (SD) BDI pre-treatment score & $30.8(9.5)$ & $30.5(8.9)$ & $31.6(9.7)$ & $31.2(7.8)$ & $29.6(9.5)$ & $29.5(10.4)$ \\
\hline Mean (SD) BAl pre-treatment score & $22.8(10.0)$ & $21.2(10.2)$ & $25.4(10.1)$ & $22.8(12.2)$ & $19.2(9.0)$ & $19.3(7.1)$ \\
\hline Mean (SD) BDI post-treatment score & $13.0(9.8)$ & $17.4(9.8)$ & $12.9(10.1)$ & $17.3(10.8)$ & $13.0(10.0)$ & $17.6(9.0)$ \\
\hline Mean (SD) BAI post-treatment score & $10.6(7.6)$ & $16.7(11.8)$ & $9.6(5.4)$ & $17.6(14.3)$ & $11.6(9.9)$ & $15.3(7.1)$ \\
\hline Mean (SD) $\triangle \mathrm{BDI}$ score (post-treatment - pre-treatment) & $-18.6(10.0)$ & $-13.2(12.8)$ & $-20.4(12.0)$ & $-14.5(10.4)$ & $-16.6(7.3)$ & $-11.5(16.1)$ \\
\hline Mean (SD) $\triangle$ BAI score (post-treatment - pre-treatment) & $-11.2(9.4)$ & $-4.3(8.3)$ & $-14.5(10.1)$ & $-5.0(9.8)$ & $-7.5(7.2)$ & $-3.1(6.0)$ \\
\hline Mean (SD) maternal age in years & $32.9(5.9)$ & $31.0(5.8)$ & $32.2(6.5)$ & $29.2(5.6)$ & $33.7(5.7)$ & $33.6(5.2)$ \\
\hline Mean (SD) gestational age in weeks & $19.9(7.7)$ & $21.0(6.0)$ & $21.2(8.0)$ & $22.6(6.1)$ & $18.3(7.2)$ & $19.0(5.5)$ \\
\hline Antidepressant use (\%) & 7.1 & 22.7 & 14.3 & 26.7 & - & 11.1 \\
\hline \multicolumn{7}{|l|}{ Marital status (\%) } \\
\hline - Married & 57.7 & 65.2 & 46.7 & 69.2 & 72.7 & 60.0 \\
\hline - De Facto & 34.6 & 21.7 & 46.7 & 15.4 & 18.2 & 30.0 \\
\hline - Separated & - & 8.7 & - & 7.7 & - & 10.0 \\
\hline - Single & 7.7 & 4.3 & 6.7 & 7.7 & 9.1 & - \\
\hline \multicolumn{7}{|l|}{ Birth location (\%) } \\
\hline - Australia & 73.1 & 82.6 & 66.7 & 84.6 & 81.8 & 80.0 \\
\hline - Other & 26.9 & 17.4 & 33.3 & 15.4 & 18.2 & 20.0 \\
\hline \multicolumn{7}{|l|}{ Income (\%) } \\
\hline - Up to $\$ 20,000$ & - & 4.5 & - & - & - & 10.0 \\
\hline$-\$ 20,001-\$ 40,000$ & 8.0 & 22.7 & 7.1 & 25.0 & 9.1 & 20.0 \\
\hline$-\$ 40,001-\$ 60,000$ & 20.0 & 13.6 & 28.6 & 16.7 & 9.1 & 10.0 \\
\hline$-\$ 60,001-\$ 80,000$ & 28.0 & 27.3 & 21.4 & 33.3 & 36.4 & 20.0 \\
\hline - >\$80,001 & 32.0 & 31.8 & 28.6 & 25.0 & 36.4 & 40.0 \\
\hline - Do not wish to divulge & 12.0 & - & 14.3 & - & 9.1 & - \\
\hline \multicolumn{7}{|l|}{ Highest level of education (\%) } \\
\hline - Did not finish school & 3.8 & 12.0 & 6.7 & 21.4 & - & - \\
\hline - High School & 7.7 & 24.0 & 13.3 & 21.4 & - & 27.3 \\
\hline - Certificate Level/Apprenticeship & 23.1 & 4.0 & 33.3 & - & 9.1 & 9.1 \\
\hline - Advanced Diploma & 19.2 & 4.0 & 6.7 & 7.1 & 36.4 & - \\
\hline - Bachelor degree & 11.5 & 24.0 & 20.0 & 28.6 & - & 18.2 \\
\hline - Graduate diploma/certificate & 19.2 & 16.0 & 6.7 & 7.1 & 36.4 & 27.3 \\
\hline - Postgraduate Degree & 15.4 & 16.0 & 13.3 & 14.3 & 18.2 & 18.2 \\
\hline
\end{tabular}

significance level $p<0.01$. Trends toward lower DNA methylation in the CBT group compared to the TAU group were seen in the OXTR, MEST, MEG3, H19, and $C R H R 2$ genes. Table 6 of the Appendix shows the probes of the candidate genes that were differentially methylated at a nominal significance level $p<0.01$.

The glucocorticoid receptor (NR3C1) gene and allocation Mean DNA methylation of 34 promoter-associated NR3C1 probes (Table 7 in Appendix) did not differ significantly between the intervention and control group (mean $\Delta \beta=0.002$, $95 \%$ CI -0.010 to 0.011 ). One probe, cg26464411, showed a trend toward lower methylation in the intervention group (Table 7 in Appendix, Fig. 2).

\section{Association between genome-wide DNA methylation and baseline depression/anxiety Depression}

Linear regression analysis (adjusted for birth weight, HM850 array chip position, sex, age, and allocation) revealed a total of 3065 differentially methylated probes at a nominal significance level $(p<0.01)$ between the groups of children from the antenatally severely depressed women versus the group of children from the antenatally mildly depressed women. Mean DNA methylation values were not significantly different between children born to the severely depressed and the mildly depressed women (mean $\Delta \beta=0.000895 \% \mathrm{CI}-0.007$ to $0.008, p=0.95)$. The top 100 differentially methylated probes according to depression severity at baseline are 
Table 2 Current characteristics of women and their children participating in a DNA methylation study

\begin{tabular}{|c|c|c|}
\hline Current demographics & $\mathrm{CBT}(n=12)$ & $\operatorname{TAU}(n=11)$ \\
\hline Mean (SD) BDI score & $16.1(13.3)$ & $14.9(11.2)$ \\
\hline Mean (SD) BAl score & $11.3(8.9)$ & $10.9(10.2)$ \\
\hline Mean (SD) maternal age in years & $40.0(4.9)$ & $40.6(4.7)$ \\
\hline Antidepressant use, $n$ (\%) & $2(16.7)$ & $6(54.4)$ \\
\hline Mean (SD) child age in years & $5.7(1.2)$ & $5.9(1.0)$ \\
\hline Mean (SD) child birth weight in grams & 3547 (332) & $3520(590)$ \\
\hline Gender (boys) (\%) & 58.3 & 63.6 \\
\hline \multicolumn{3}{|l|}{ Birth location (\%) } \\
\hline - Australia & 81.8 & 80.0 \\
\hline - Other & 18.2 & 20.0 \\
\hline \multicolumn{3}{|l|}{ Marital status (\%) } \\
\hline - Married & 66.7 & 54.4 \\
\hline - De Facto & 8.3 & 18.2 \\
\hline - Separated & 8.3 & 18.2 \\
\hline - Single & 16.7 & 9.1 \\
\hline \multicolumn{3}{|l|}{ Highest level of education (\%) } \\
\hline - Did not finish school & - & - \\
\hline - High School & - & 27.3 \\
\hline - Certificate Level/Apprenticeship & 8.3 & 9.1 \\
\hline - Advanced Diploma & 8.3 & - \\
\hline - Bachelor degree & 25.0 & 9.1 \\
\hline - Graduate diploma/certificate & 41.7 & 18.2 \\
\hline - Postgraduate Degree & 16.7 & 36.4 \\
\hline \multicolumn{3}{|l|}{ Income (\%) } \\
\hline - Up to $\$ 20,000$ & - & 18.2 \\
\hline$-\$ 20,001-\$ 40,000$ & 8.3 & 18.2 \\
\hline$-\$ 40,001-\$ 60,000$ & - & 9.1 \\
\hline$-\$ 60,001-\$ 80,000$ & 8.3 & 9.1 \\
\hline$->\$ 80,001$ & 83.3 & 45.5 \\
\hline - Do not wish to divulge & - & - \\
\hline Smoking ${ }^{a}(\%)$ & 8.3 & 9.1 \\
\hline Alcohol $^{\mathrm{b}}(\%)$ & 58.3 & 27.3 \\
\hline
\end{tabular}

$C B T$ cognitive behavioral therapy, TAU treatment as usual

${ }^{a, b}$ Defined as "currently consuming one or more alcoholic units per week or smoking one or more cigarettes per week"

presented in Table 8 (Appendix). After correcting for multiple testing (corrected $p \leq 0.01$ ), no probes remained significantly associated with maternal depression severity in pregnancy, prior to treatment.

\section{Anxiety}

Linear regression analysis (adjusted for birth weight, HM850 array chip position, sex, age, and allocation) revealed a total of 3292 differentially methylated probes at a nominal significance level $(p<0.01)$ between the groups of children from the antenatally severely anxious women versus the group of children from the antenatally mildly anxious women. Mean DNA methylation values were not significantly different between the children born to severely anxious and the mildly anxious women (mean $\Delta \beta=0.000295 \% \mathrm{CI}-0.004$ to 0.005 , $p<0.01$ ). The top 100 differentially methylated probes according to anxiety severity at baseline are presented in Table 9 in Appendix. After correcting for multiple testing (corrected $p \leq 0.01$ ), no probes remained significantly associated with maternal anxiety severity in pregnancy, prior to treatment.

\section{Candidate gene-specific DNA methylation and baseline depression/anxiety Depression}

Table 10 (Appendix) shows the results of the unpaired Mann-Whitney-Wilcoxon tests, comparing mean DNA methylation of 16 candidate genes between the groups of children from the highly depressed and the mildly depressed women. No genes were significantly differentially methylated at a nominal significance level $p<0.01$. Table 11 of the Appendix shows the probes of the candidate genes that were differentially methylated according to depression symptom severity at a nominal significance level $p<0.01$.

\section{Anxiety}

Table 12 (Appendix) shows the results of the unpaired Mann-Whitney-Wilcoxon tests, comparing mean DNA methylation of 16 candidate genes between the groups of children from the highly anxious and the mildly anxious women. No genes were significantly differentially methylated at a nominal significance level $p<0.01$. A trend toward higher DNA methylation was seen in the children from the highly anxious mothers compared to the children of mildly anxious mothers in the MEST gene. Table 11 of the Appendix shows the probes of the candidate genes that were differentially methylated according to anxiety symptom severity at a nominal significance level $p<0.01$.

\section{The glucocorticoid receptor (NR3C1) gene and baseline depression/anxiety \\ Depression}

Mean DNA methylation of 34 promoter-associated NR3C1 probes (Table 13, Appendix) did not differ significantly between the groups of children from the highly depressed and the mildly depressed women (mean $\Delta \beta=0.006$, 95\% CI 0.005 to 0.020 ).

\section{Anxiety}

Mean DNA methylation of 34 promoter-associated NR3C1 probes did not differ significantly between the groups of children from the highly anxious and the mildly anxious women (mean $\Delta \beta=0.006,95 \% \mathrm{CI}-0.005$ to 0.020 ). Two 
Table 3 Top 100 differentially methylated probes according to intervention

\begin{tabular}{|c|c|c|c|c|c|}
\hline CpG & $p$ & Adjusted $p^{a}$ & Gene & Gene region & $\Delta \beta$ \\
\hline cg19908420 & $3.40 \mathrm{E}-06$ & 0.999997557 & & & 0.049137862 \\
\hline cg15495292 & 4.01E-06 & 0.999997557 & $A \mid G 1$ & Body & 0.079710136 \\
\hline cg05155812 & $1.56 \mathrm{E}-05$ & 0.999997557 & SUN1 & TSS1500 & -0.280713404 \\
\hline cg18818484 & $2.20 \mathrm{E}-05$ & 0.999997557 & PTCHD2 & & 0.022078691 \\
\hline cg17622532 & $2.21 \mathrm{E}-05$ & 0.999997557 & & & 0.024836631 \\
\hline cg14034519 & $2.27 \mathrm{E}-05$ & 0.999997557 & $S N X 1$ & Body & 0.053471841 \\
\hline cg26436424 & $3.24 \mathrm{E}-05$ & 0.999997557 & NGEF & Body & 0.033261363 \\
\hline cg21494953 & $3.48 \mathrm{E}-05$ & 0.999997557 & C5orf23 & TSS1500 & 0.036133838 \\
\hline cg19232929 & $3.58 \mathrm{E}-05$ & 0.999997557 & & & 0.054387673 \\
\hline cg22342380 & 3.86E-05 & 0.999997557 & & & 0.03688025 \\
\hline cg13719771 & $5.98 \mathrm{E}-05$ & 0.999997557 & NDUFA9 & Body & 0.13765872 \\
\hline cg10356363 & $6.06 \mathrm{E}-05$ & 0.999997557 & CEBPB & TSS1500 & 0.026639222 \\
\hline cg05205351 & $6.20 \mathrm{E}-05$ & 0.999997557 & NOP56 & Body & 0.05930508 \\
\hline cg14231326 & $6.23 \mathrm{E}-05$ & 0.999997557 & & & 0.031289864 \\
\hline cg14358699 & 7.14E-05 & 0.999997557 & & & 0.047991502 \\
\hline cg06961812 & $8.01 \mathrm{E}-05$ & 0.999997557 & PRODH2 & Body & 0.058582642 \\
\hline cg16007230 & 8.39E-05 & 0.999997557 & $A B C C 3$ & ExonBnd & 0.036161879 \\
\hline cg25968469 & $8.53 \mathrm{E}-05$ & 0.999997557 & ARHGAP22 & Body & 0.056699144 \\
\hline cg23619591 & $8.80 \mathrm{E}-05$ & 0.999997557 & C19orf81 & Body & 0.057592082 \\
\hline cg09240747 & 0.000101189 & 0.999997557 & & & 0.067301777 \\
\hline cg18077049 & 0.000101567 & 0.999997557 & GLRA3 & Body & 0.116790545 \\
\hline cg24435401 & 0.000110721 & 0.999997557 & NPAS4 & TSS1500 & 0.021387283 \\
\hline cg23274420 & 0.000110944 & 0.999997557 & & & 0.068615769 \\
\hline cg09223928 & 0.000111509 & 0.999997557 & & & 0.030359585 \\
\hline cg18666104 & 0.000115314 & 0.999997557 & CORO1C & Body & 0.058415174 \\
\hline cg16273469 & 0.000115391 & 0.999997557 & & & 0.036049214 \\
\hline cg00541777 & 0.000120288 & 0.999997557 & COLEC11 & TSS1500 & 0.120518141 \\
\hline cg06646082 & 0.0001208 & 0.999997557 & BTBD17 & TSS1500 & 0.0430183 \\
\hline cg037111840 & 0.000127893 & 0.999997557 & PLXNA1 & Body & 0.043191584 \\
\hline cg19465002 & 0.000130791 & 0.999997557 & & & 0.033852961 \\
\hline cg14687471 & 0.000134464 & 0.999997557 & NBR2 & Body & 0.023128809 \\
\hline cg27243560 & 0.000134814 & 0.999997557 & & & 0.031689225 \\
\hline cg05510714 & 0.000135017 & 0.999997557 & KYNU & Body & 0.153887531 \\
\hline cg12987887 & 0.000136898 & 0.999997557 & UPB1 & ExonBnd & -0.01972518 \\
\hline cg26836955 & 0.000138572 & 0.999997557 & LONP1 & Body & 0.039104166 \\
\hline cg26330841 & 0.000138665 & 0.999997557 & & & 0.032962344 \\
\hline cg16720807 & 0.000142967 & 0.999997557 & FAM176A & $5^{\prime} U T R$ & 0.042119403 \\
\hline cg01440210 & 0.000143289 & 0.999997557 & & & 0.030341728 \\
\hline cg17068417 & 0.000144326 & 0.999997557 & EEFSEC & Body & 0.030665165 \\
\hline cg15313810 & 0.000144443 & 0.999997557 & ST6GALNAC4 & Body & 0.029787439 \\
\hline cg07545731 & 0.000147518 & 0.999997557 & COL22A1 & Body & 0.04468122 \\
\hline cg14684297 & 0.000150469 & 0.999997557 & ARHGAP33 & $5^{\prime} U T R$ & 0.032019831 \\
\hline cg10727673 & 0.000154265 & 0.999997557 & TMEM22 & TSS1500 & 0.089444195 \\
\hline cg04798314 & 0.000155738 & 0.999997557 & SMYD3 & Body & 0.323390033 \\
\hline
\end{tabular}


Table 3 Top 100 differentially methylated probes according to intervention (Continued)

\begin{tabular}{|c|c|c|c|c|c|}
\hline$\overline{C p G}$ & $p$ & Adjusted $p^{a}$ & Gene & Gene region & $\Delta \beta$ \\
\hline cg11035122 & 0.000160944 & 0.999997557 & MIR758 & TSS1500 & 0.055539324 \\
\hline cg12360330 & 0.000168181 & 0.999997557 & CENPJ & Body & 0.032193572 \\
\hline cg07469546 & 0.000172234 & 0.999997557 & & & 0.014405304 \\
\hline cg17785398 & 0.000172977 & 0.999997557 & KCNJ6 & Body & 0.022656857 \\
\hline cg18291664 & 0.000173083 & 0.999997557 & PRKAR1B & Body & 0.040654976 \\
\hline cg09319487 & 0.000181803 & 0.999997557 & & & 0.033053753 \\
\hline cg11510586 & 0.000186082 & 0.999997557 & & & 0.107251714 \\
\hline cg25441526 & 0.000188457 & 0.999997557 & WDFY4 & Body & 0.025251026 \\
\hline cg19379103 & 0.000188787 & 0.999997557 & SSBP3 & Body & 0.031870653 \\
\hline cg19769811 & 0.00019183 & 0.999997557 & RASGRF2 & TSS1500 & 0.046395706 \\
\hline cg26221509 & 0.000199233 & 0.999997557 & SCUBE1 & Body & 0.039685931 \\
\hline cg14700416 & 0.000199451 & 0.999997557 & SPOCK3 & $5^{\prime} U T R$ & 0.049430209 \\
\hline cg22746421 & 0.000200331 & 0.999997557 & & & 0.02669027 \\
\hline cg23553242 & 0.000200938 & 0.999997557 & USP2 & Body & 0.043740484 \\
\hline cg06617093 & 0.000206244 & 0.999997557 & & & 0.032231234 \\
\hline cg08670534 & 0.000206305 & 0.999997557 & COL2A1 & Body & 0.032117847 \\
\hline cg15791944 & 0.000212127 & 0.999997557 & & & 0.055152706 \\
\hline cg17562896 & 0.000216404 & 0.999997557 & SV2C & Body & 0.037479302 \\
\hline cg02018176 & 0.000217297 & 0.999997557 & KIAA1530 & Body & 0.047057842 \\
\hline cg11576176 & 0.000220243 & 0.999997557 & GSX2 & 1stExon & 0.03556139 \\
\hline cg09480336 & 0.0002295 & 0.999997557 & POLD1 & Body & 0.03212232 \\
\hline cg21592262 & 0.000233681 & 0.999997557 & & & 0.06371313 \\
\hline cg12472342 & 0.000234117 & 0.999997557 & & & -0.069235248 \\
\hline cg18361948 & 0.00023564 & 0.999997557 & & & 0.029932491 \\
\hline cg00945089 & 0.000236572 & 0.999997557 & GFRA1 & Body & 0.033266209 \\
\hline cg07442357 & 0.000238546 & 0.999997557 & & & 0.01892614 \\
\hline cg09193498 & 0.000239232 & 0.999997557 & SEZ6 & Body & 0.042776024 \\
\hline cg02438610 & 0.000240811 & 0.999997557 & SUN1 & TSS1500 & -0.013139753 \\
\hline cg15037661 & 0.00024103 & 0.999997557 & NR1D2 & TSS1500 & 0.00946764 \\
\hline cg26264656 & 0.000243011 & 0.999997557 & SKI & Body & 0.034797294 \\
\hline cg24367840 & 0.000243465 & 0.999997557 & PSMD14 & Body & 0.057487682 \\
\hline cg05289897 & 0.000259274 & 0.999997557 & & & 0.012403078 \\
\hline cg16419764 & 0.000261486 & 0.999997557 & CDYL & Body & 0.026043028 \\
\hline cg00248302 & 0.000266776 & 0.999997557 & FCRL5 & Body & 0.028022889 \\
\hline cg24900542 & 0.000269678 & 0.999997557 & & & 0.085875055 \\
\hline cg15078841 & 0.000272298 & 0.999997557 & & & 0.022837528 \\
\hline cg12541879 & 0.000282436 & 0.999997557 & PTPRN2 & Body & 0.056208383 \\
\hline cg01976641 & 0.000283246 & 0.999997557 & & & 0.05497368 \\
\hline cg17121322 & 0.000286514 & 0.999997557 & & & 0.025193249 \\
\hline cg17547875 & 0.000288231 & 0.999997557 & & & 0.01236688 \\
\hline cg18169610 & 0.000296554 & 0.999997557 & CD81 & Body & 0.038708 \\
\hline cg04801704 & 0.000304651 & 0.999997557 & TLL2 & Body & 0.025096532 \\
\hline cg23425290 & 0.000307508 & 0.999997557 & $A B C C 1$ & Body & 0.023343856 \\
\hline cq22680931 & 0.00030882 & 0.999997557 & TMEM167B & TSS1500 & 0.122894387 \\
\hline
\end{tabular}


Table 3 Top 100 differentially methylated probes according to intervention (Continued)

\begin{tabular}{|c|c|c|c|c|c|}
\hline$\overline{\mathrm{CpG}}$ & $p$ & Adjusted $p^{\mathrm{a}}$ & Gene & Gene region & $\Delta \beta$ \\
\hline$\overline{c g 01723825}$ & 0.000310423 & 0.999997555 & UR/1 & TSS200 & 0.039217642 \\
\hline cg16261251 & 0.000311941 & 0.999997557 & & & 0.06722457 \\
\hline cg01400541 & 0.000314878 & 0.999997557 & C10orf128 & Body & 0.042719378 \\
\hline cg26796807 & 0.000318004 & 0.999997557 & & & 0.04717045 \\
\hline cg10038145 & 0.000319876 & 0.999997557 & $P O R$ & Body & 0.045738894 \\
\hline cg09078103 & 0.000320468 & 0.999997557 & SNX9 & Body & 0.027261168 \\
\hline cg08880699 & 0.000322485 & 0.999997557 & & & 0.043133838 \\
\hline cg03116452 & 0.00032398 & 0.999997557 & PLD3 & $5^{\prime}$ UTR & 0.034421382 \\
\hline cg03071994 & 0.000324145 & 0.999997557 & NR4A1 & Body & 0.029626215 \\
\hline cg21485062 & 0.000324634 & 0.999997557 & C7orf25 & Body & 0.024308813 \\
\hline cg11504793 & 0.000326763 & 0.999997557 & NOL4L & Body & 0.025196146 \\
\hline cg04837576 & 0.00032871 & 0.999997557 & ADRBK2 & Body & 0.030823149 \\
\hline
\end{tabular}

$\Delta \beta=$ mean $\beta$ (treatment as usual) - mean $\beta$ (cognitive behavioral therapy)

TSS transcription start site, UTR untranslated region

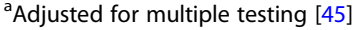

probes, $\operatorname{cg} 07515400$ and $\operatorname{cg} 22402730$, showed a trend toward higher DNA methylation in the children from severely anxious mothers (Table 13, Appendix).

\section{Discussion}

In this follow-up of one of the first randomized controlled trials on the effect of antenatal psychological depression treatment (CBT) on children's DNA methylation patterns, we found no robust evidence of widespread methylation differences between children of women in the control or intervention group. However, at a pre-specified nominal significance level of $p<0.01,4780$ differentially methylated probes according to allocation pointed to an overall $2.7 \%$ lower DNA methylation level of probes in children from the intervention group. Applying a candidate approach, non-significant trends toward lower DNA methylation in the intervention group were seen in OXTR, MEST, MEG3, $H 19$, and CRHR2. We did not find a significant difference in mean DNA methylation of 34 NR3C1 promoter-associated probes between the intervention and control groups. Nevertheless, the majority of probes (68\%) showed lower DNA methylation in the intervention group compared to the control group, with cg26464411 as topmost differentially methylated probe, a CpG site that has been associated with depression in earlier studies [25, 26]. Whether these trends are persistent and clinically relevant remains to be determined in future studies with larger sample size and longer follow-up.

Of the top five probes that were most differentially methylated between the intervention and the control group, three corresponded to annotated genes: cg15495292 on the AIG1 gene, which is a gene involved in androgen regulation; cg18818484 on the PTCHD2 gene, which is involved in neuronal proliferation and differentiation; and cg05155812 on SUN1, a gene that potentially plays a role in neuronal migration and cerebellar development. These findings may be

Table 4 Top 10 differentially methylated genes according to allocation

\begin{tabular}{|c|c|c|c|c|c|}
\hline CpG & $p$ & Adjusted $p^{\mathrm{a}}$ & Gene & Gene region & $\Delta ß$ \\
\hline cg19908420 & $3.40 \mathrm{E}-06$ & 0.999998 & & & 0.049137862 \\
\hline cg15495292 & 4.01E-06 & 0.999998 & $A / G 1$ & Body & 0.079710136 \\
\hline cg05155812 & 1.56E-05 & 0.999998 & SUN1 & TSS1500 & $-? 0.280713404$ \\
\hline cg18818484 & $2.20 \mathrm{E}-05$ & 0.999998 & PTCHD2 & Body & 0.022078691 \\
\hline cg17622532 & 2.21E-05 & 0.999998 & & & 0.024836631 \\
\hline cg14034519 & 2.27E-05 & 0.999998 & $S N X_{1}$ & Body & 0.053471841 \\
\hline cg26436424 & $3.24 \mathrm{E}-05$ & 0.999998 & NGEF & Body & 0.033261363 \\
\hline cg21494953 & 3.48E-05 & 0.999998 & C5orf23 & TSS1500 & 0.036133838 \\
\hline cg19232929 & 3.58E-05 & 0.999998 & & & 0.054387673 \\
\hline cg22342380 & 3.86E-05 & 0.999998 & & & 0.03688025 \\
\hline
\end{tabular}

? $\$=$ mean $ß($ TAU) - mean $ß(C B T)$

CBT cognitive behavioral therapy, TAU treatment as usual, TSS transcription start site, UTR untranslated region

${ }^{\mathrm{a} C o r r e c t e d ~ f o r ~ m u l t i p l e ~ t e s t i n g ~[46] ~}$ 
relevant as the desired effect of a prenatal intervention would be to target genes that mediate the associations of prenatal stress, depression or anxiety with adverse neurodevelopmental disorders in children [27, 28]. Our results are promising, but evidently replication in larger studies is necessary.

Additionally, we revealed trends toward lower DNA methylation in children from the intervention group compared to the control group in 5 out of 16 candidate genes that have previously been associated with prenatal exposure to maternal stress, depression, or anxiety. These trends were observed in OXTR, the gene coding for the Oxytocin receptor; the MEST gene, a gene involved in metabolism; MEG3, a long noncoding RNA; H19, an imprinted gene; and CRHR1, a gene for corticotrophin releasing hormone receptors. We did not find a significant difference in mean DNA methylation between the intervention and control group on the promoter region of the NR3C1 gene, coding for the glucocorticoid receptor. Nevertheless, cg26464411 showed a trend toward lower DNA methylation in the intervention group. This CpG site has been positively correlated with depressive symptoms or hypercortisolism in earlier studies $[25,26]$. Although our results were not significant, the trends we have observed were in line with our expectations, based on earlier findings from observational studies showing increased methylation of NR3C1 in newborns and young children of antenatally stressed, depressed, or anxious women $[20,29]$, which was associated with increased stress responses $[21,30]$.

The women in the current study were treated at a mean of 18.6 weeks gestational age, and it may be possible that the effect of treatment on offspring DNA methylation would have been stronger if the women had been treated earlier in their pregnancies. Increased attention is currently focused on the period of early pregnancy, and even the preconception period, as an important time window for adverse environmental factors inducing prenatal programming, which has been shown in animal studies [18]. Further evidence in humans is derived from studies examining prenatal famine, in which the largest effect on offspring methylation was found after prenatal exposure to undernutrition in early pregnancy [31]. We did not test for an interaction between allocation status and gestational age on mean methylation in candidate genes because of the lack of significance in the initial analyses, but in larger future studies, exploring moderation through gestational age would be highly informative to identify treatment effects on DNA methylation during specific stages of pregnancy.

A limitation of the study was a lack of statistical power, as we were only able to include approximately half $(23 / 54=$ $43 \%$ ) of the original sample in this follow-up. Nevertheless, associations between prenatal stress and methylation status of NR3C1 have been reported in studies with a similar sample size [30, 32]. It was of interest that women who participated in the current follow-up study had lower levels of depression and anxiety at baseline compared to the participants that were lost to follow-up (Table 1). Also, they were observed to have higher incomes and were more highly educated at baseline. However, attrition bias is not likely to have occurred as this was the case in both groups [33]. Despite no formal statistical tests being conducted [34], it was evident that the difference in anxiety (BAI) scores before and after treatment between the intervention and control group was twice as high in the non-responders compared to the responders (14.5 versus 7.5), indicating that women with greater response to treatment were relatively underrepresented in the current sample. Additionally, some women in the control group also reported accessing psychological or medical treatment outside the trial [24]. This, and the lower participation of those who responded better to treatment, might have led to an underestimation of the effect of therapy on methylation profiles in the children in the current study.

Although both groups were reasonably balanced in terms of psychological and sociodemographic factors at the time of follow-up, it is still possible that other, unmeasured factors are (partly) responsible for the trends observed in the children's epigenetic profiles according to allocation status. Because of the small sample size of our study, we chose to include only those variables that were likely to attribute mostly to the variation in DNA methylation, such as child gender, age, birth weight, and income. We did not include educational attainment, although this also appeared to be somewhat higher in the intervention group (although not statistically significant, results not shown). In addition,

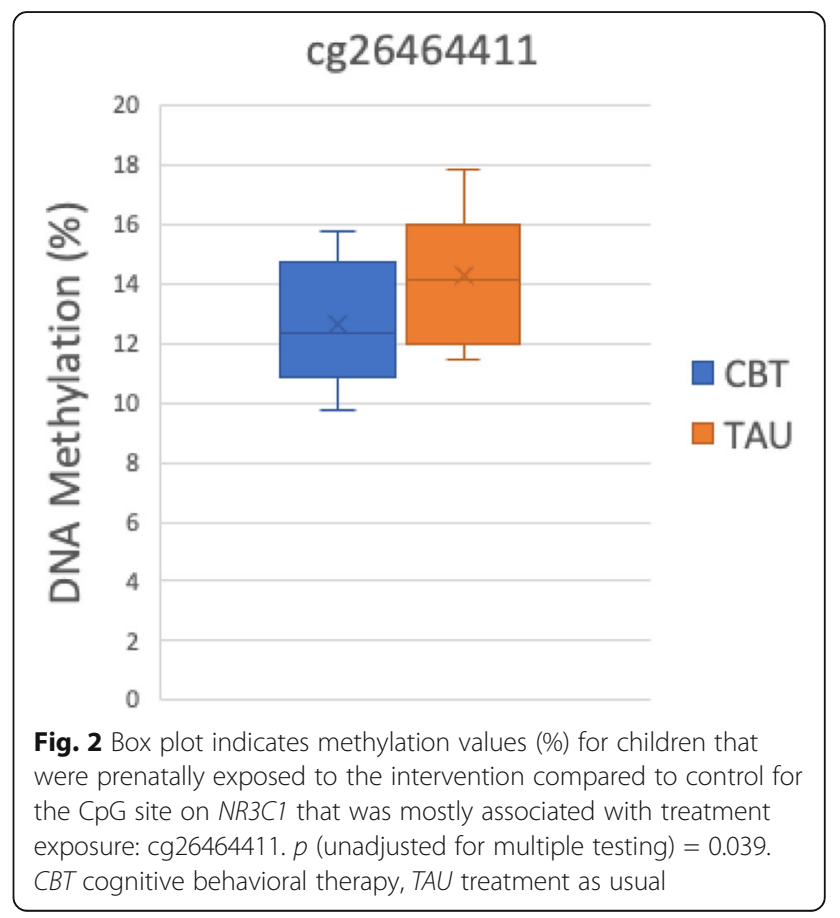


maternal body composition in pregnancy, pregnancy complications, and mode of delivery were not recorded in the original study files, and hence, not included in the current study. As these factors may act as mediators in the causal path from improved mood in pregnancy to better child outcomes, in future studies these variables should be included as well. Nevertheless, we did have access to the children's birth weight, an important marker for general health of the baby, which showed to be similar between both groups. Also, we were unable to control for PC5 in the analyses, as none of the variables included in the model was associated with PC5. Nevertheless, the contribution fraction of PC5 to the variation in DNA methylation was very marginal compared to the contribution fraction of $\mathrm{PC} 1, \mathrm{PC} 2, \mathrm{PC} 3$, and $\mathrm{PC} 4$, which were associated with known variables and therefore were controlled for in our analyses. Finally, we did not adjust for cellular heterogeneity in our study. The most widely applied method is the reference-based deconvolution method originally described by Houseman et al., which permits the estimation of the proportion of various cell types within a sample based on existing reference data sets [35]. For blood, several studies have analyzed the methylation profile of the specific cell- types present in whole blood, which can serve as reference data. However, for saliva, this has not been performed systematically, but studies that have applied the Houseman deconvolution method on salivary genome wide DNA methylation data (combining reference methylomes from leucocyte subtypes and buccal epithelial cells references methylomes) have shown that saliva is less heterogenic compared to blood [36].

The impact of the postnatal environment on methylation profiles in children also cannot be ignored. Exposure to stressful life events from birth to adolescence has been associated with higher NR3C1 methylation [37]. Although in

\section{a PCA plot 1st of 10 PRINCIPAL COMPONENTS}

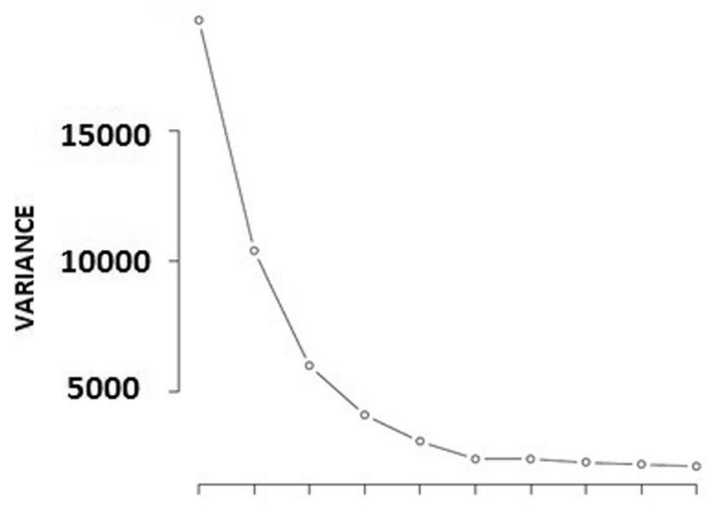

$\begin{array}{llllllllll}1 & 2 & 3 & 4 & 5 & 6 & 7 & 8 & 9 & 10\end{array}$

b

PCA-TRAITS RELATIONSHIPS

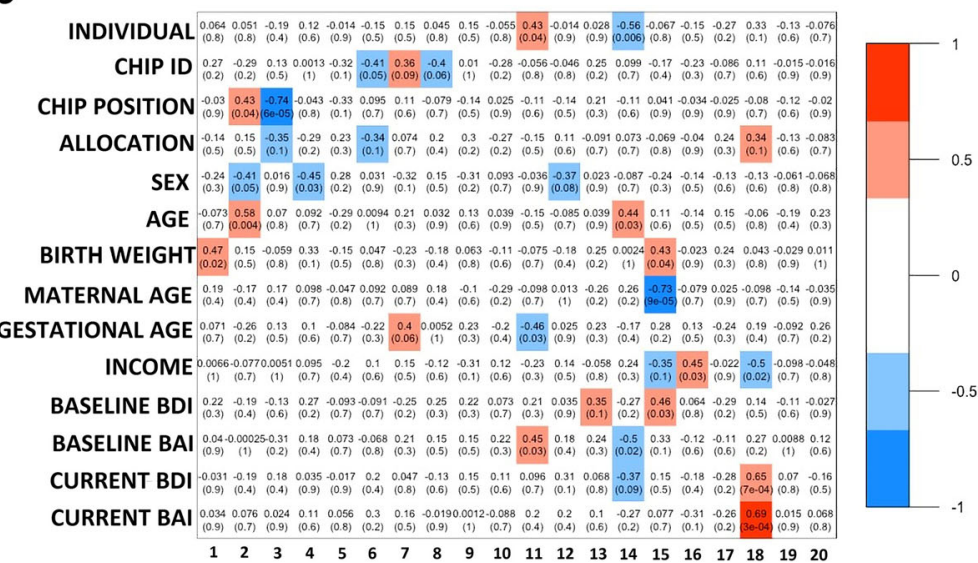

Fig. 3 Principal component analysis results of the variation in the HM850 methylation data. Principal component analysis revealed birth weight as the major contributor to variation in the dataset with intervention status as the fifth largest contributor to variation in buccal cell DNA methylation profiles. a Scree plot generated with $M$ values for 770,668 probes on the HM850 array. Variance is shown on the $y$-axis, principal components are shown on the $x$-axis. $\mathbf{b}$ Heatmap showing correlation coefficients, direction of correlations, and $p$ values (bracketed) between principal components and various clinical parameters. Shaded boxes indicate correlations between principal components and clinical parameters (set at $p \leq 0.1$ ) 
both intervention and control group, more women were currently using antidepressant medication compared to when they were pregnant at enrollment of the original study, this was much more pronounced in the control group (relative increase of 43.3\%) compared to the intervention group (relative increase of 16.7\%). These observations may be consistent with a potential longer-term beneficial effect of treatment in the women, which in turn, might have positively affected child outcomes. Women from the intervention group also reported higher incomes compared to baseline, which was not the case in the control group, although including income as additional covariate did not significantly alter the results. To be able to isolate the effect of antenatal CBT on offspring DNA methylation in utero, prior to any postnatal confounding, evidence from trials that include cord blood and/or placenta samples for DNA methylation (and gene expression) are needed.

Finally, it has not yet been fully elucidated how maternal depression affects child adversity. Nevertheless, epigenetic modification of fetal genes in response to increased cortisol exposure, either directly or via a decrease in placental inactivation, has been widely accepted as a potential underlying mechanism. Although our study findings could not robustly support this hypothesis, the trends observed are in line with earlier evidence. The existing evidence is nearly exclusively based on findings from experiments in animals and observational human studies. The fact that the exploratory findings from this novel experimental study in humans are in line with the available evidence is therefore promising. It must be noted that we mostly looked at statistically significant results at an uncorrected $p$-value level. The results of our study should therefore be interpreted with caution. Although the observed effect sizes were small, with mean differences of $1-5 \%$ in methylation status, they are in line with earlier evidence [20]. Because of the lack of studies with a comparable study design, it is not yet possible to replicate our findings in a similar trial; however, plans for a larger trial are currently in progress.

\section{Conclusion}

We found preliminary evidence of a possible effect of cognitive behavioral therapy during pregnancy on widespread methylation and a non-significant trend towards lower methylation of a specific CpG site previously linked to depressive symptoms and child maltreatment in the intervention group. However, none of the effects survived correction for multiple testing. Larger studies are now warranted.

\section{Methods}

\section{Study population}

For the BBB study, women aged 18 years or over, and less than 30 weeks pregnant were recruited through screening programs at the Northern Hospital and Mercy Hospital for Women, Melbourne, Australia, and via
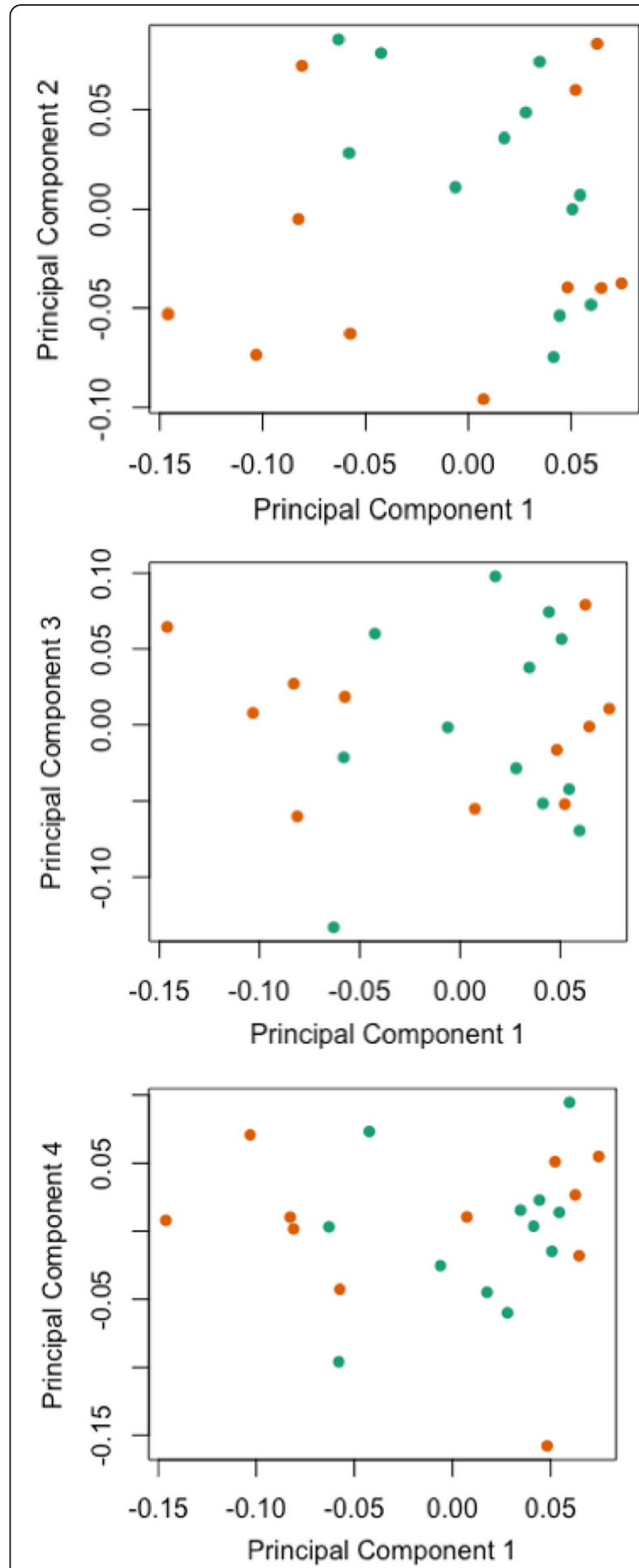

Fig. 4 MDS plots, with samples colored according to CBT (turquoise)/TAU (orange) status, showing the relatedness of samples over the first four principal components of variation. CBT cognitive behavioral therapy, TAU treatment as usual 
other health professionals and services in the public (e.g., obstetricians, GPs, and PaNDA; a Perinatal Anxiety and Depression helpline) and private sector (e.g., Northpark Private Hospital). The participating institutions were reached through advertisement and encouraged to refer women with suspected clinical depression. Women scoring 13 points or higher on the Edinburgh Postnatal Depression Scale (EPDS), the optimal score for detecting depression during pregnancy [38], were referred to the study for assessment by a psychologist if they consented. They were included in the study if they met DSM-IV criteria for a minor or major depressive disorder or an adjustment disorder with mixed depression and anxiety [39]. Severity of depression and anxiety symptoms was measured with the Beck Depression and Anxiety Inventories $[40,41]$. Women with comorbid axis I disorders or medical conditions that were likely to interfere with study participation, risk requiring crisis management, participation in other psychological programs, or significant difficulty with English were excluded [24]. Women included in the study $(N=54)$ were randomized to receive pregnancy-specific CBT $(N=28)$ or TAU $(N=26)$. The CBT program consisted of seven individual sessions and one partner-session. TAU consisted of case-management by a midwife or a general practitioner and referral to other services of agencies as necessary. For ease of interpretation, in the results sections of this paper, the group of children of mothers from the CBT group will be referred to as the "intervention" group, and the group of children of mothers from the TAU group will be referred to as the "control" group. For participation in the current study, starting approximately 5 years after the BBB program had ended, all participants were invited through a letter. If they agreed to participate, an appointment at the Melbourne Brain Institute was planned, and informed consent was signed prior to or on the day of their visit to the clinic. If women were not able to attend the clinic, they were invited to send a buccal sample through the mail. The study was approved by the Human Research Ethics Committees of Austin Health, Melbourne, Australia.

\section{Data collection}

A questionnaire on current sociodemographic data and current symptoms of depression and anxiety was sent to each woman's home address. Baseline demographics, including symptoms of depression and anxiety as well as the child's birth weight, were taken from the BBB study files. At the Melbourne Brain Centre, a cognitive assessment by means of the Wechsler Preschool and Primary Intelligence Scale (WWPSI-III) [42] was performed on the child, an MRI scan of the child's brain was conducted, of which results are described elsewhere, and a buccal cell sample from the child was obtained by a researcher who was blinded to the allocation status of the women.

\section{Buccal cell samples}

Buccal cells were collected using a dedicated swab (OraCollect 100, DNA Genotek Inc., Ontario, Canada). Children were instructed not to eat or drink $30 \mathrm{~min}$ prior to taking the swab. Women who were not able to visit the Melbourne Brain Centre were instructed how to apply the swab on their child, and asked to send the sample via mail. The swabs were stored at room temperature at the Parent-Infant Research Institute and transported to the Murdoch Children's Research Institute (Melbourne, Australia) for DNA extraction within 2 weeks after collection.

\section{DNA extraction and genome-wide methylation detection}

DNA extraction of all samples was performed using the NucleoBond CB20 DNA extraction kit. Purification of DNA was assessed using Nanodrop Spectrophotometry. Bisulfite conversion was performed using the EZ-96 DNA methylation kit (ZYMO Research Corporation) according to the manufacturer's instructions. DNA methylation profiling was performed at the Australian Genome Research Facility, on bisulfite converted DNA using the Illumina Infinium Methylation EPIC BeadChip Array (HM850) (Illumina), which measures CpG methylation at $>850,000$ genomic sites.

\section{Candidate gene approach}

We extracted 729 probes spanning 16 a priori selected genes for linear regression analysis. Candidate genes were those that had previously been assessed in relation to prenatal exposure to maternal stress, depression, and/or anxiety in earlier studies [20]. Genes of interest were genes encoding brain-derived neurotrophic factor (BDNF; 91 probes), corticotrophin releasing hormone (CRH; 21 probes), corticotrophin-releasing factor-binding protein (CRHBP; 25 probes), corticotrophin-releasing hormone receptors 1 and 2 (CRHR1; 41 probes, CRHR2; 40 probes), FK506 binding protein (FKBP5; 49 probes), a long noncoding RNA (H19; 57 probes), hydroxysteroid 11-beta dehydrogenase 1 and 2 (HSD11B1; 25 probes, HSD11B2; 23 probes), insulin-like growth factor (IGF2; 15 probes), maternally expressed 3 (MEG3; 87 probes), mesoderm-specific transcript homolog protein (MEST; 63 probes), the glucocorticoid receptor (NR3C1; 89 probes), the mineralocorticoid receptor (NR3C2; 50 probes), the oxytocin receptor (OXTR; 22 probes), and the serotonin transporter (SLC6A4; 31 probes) [20]. Additionally, considering the especially strong evidence for this gene, we separately analyzed the probes of the promoter region of the glucocorticoid receptor gene (NR3C1 promoter-associated probes; 34 probes) for differential methylation.

\section{Statistical analysis}

DNA methylation was defined as a continuous variable varying from 0 (completely unmethylated) to 1 (completely methylated). Methylation data were processed in $\mathrm{R}$ using 
the minfi package. Normalization of the data was performed using the SWAN method [43]. Probes on X and $Y$ chromosomes, probes that were associated with SNPs with a minor allele frequency $>1 \%$, and cross-reactive probes [44] were removed from the dataset. This resulted in data for 770,668 probes available for subsequent analysis.

\section{Sources of variation}

Main contributors to the variation in the methylation data were identified by principal component analysis (PCA). We included the following variables in the analysis to assess associations with PC's: participant ID, chip ID, HM850 array chip position, allocation, sex, child age, birth weight, maternal age, gestational age, current income, baseline depression symptoms, baseline anxiety symptoms, current depression symptoms, and current anxiety symptoms. Results of the PCA showed that the first five principal components contributed most to the variation in the methylation data, and all variables associated with any of these PC's were added as covariate in all analyses (Fig. 3a). The heatmap demonstrated that allocation was associated with the third principal component. Birth weight, child age, sex, and HM850 array chip position were associated with the first four principal components and they were included in the analyses as covariates. None of the variables included in our model was significantly associated with the fifth principal component, and this PC was therefore not included in our model as covariate (Fig. 3b). Unsupervised analysis by multidimensional scaling was conducted in order to examine sources of variation within the dataset. Beta values (methylation level) at all HM850 probes for all samples were used to produce multidimensional scaling (MDS) plots, with samples colored according to intervention (turquoise)/control (orange) status, showing the relatedness of samples over the first two principal components of variation (Fig. 4a). Coloring by intervention/control revealed no distinct separation by allocation. Additional MDS plots of samples over other principal components also failed to show a distinct separation between the two groups (Figs. 4b c).

\section{Differential methylation according to allocation}

Linear regression analysis was used to identify associations between the intervention status and epigenome-wide DNA methylation. We took into account variation associated with the covariates birth weight, HM850 array chip position, child sex and age, to account for PC1, PC2, PC3, and PC4, as identified by PCA. The Benjamini-Hochberg False-Discovery-Rate method [45] was used to correct for multiple testing. However, none of the analyses yielded significant differentially methylated probes between the intervention and control group after correcting for multiple testing.
In an explorative analysis, we extracted differentially methylated probes between the intervention and control group at a nominal significance level set at $p<0.01$, prior to correcting for multiple testing. We assessed differences in mean DNA methylation of all significant probes between the intervention and control group using an unpaired Mann-Whitney-Wilcoxon test. We additionally compared mean beta differences of 16 candidate genes, and the promoter region of the NR3C1 gene between the intervention and control group using an unpaired Mann-Whitney-Wilcoxon test.

\section{Differential methylation according to baseline depression or anxiety symptom score}

As additional explorative analyses, two separate linear regression models were also used to investigate associations between baseline depression (BDI-II score) and baseline anxiety (BAI- score) with methylation profiles in the children. For ease of interpretation, the sample was divided into two groups in both analyses. The rationale behind this approach was to explore widespread methylation variation between women with severe symptoms compared to those with mild symptoms using clinically relevant cut-offs, rather than investigating the direction of correlations between increasing depression and anxiety scores on all probes separately. Baseline depression was converted to a dichotomous variable using clinically relevant Beck questionnaire cut-offs. Women with BDI-II $\geq 29$ were classified as "highly depressed" ( $n$ $=13$ ), whereas those with a score below 29 were classified as "mildly depressed" $(n=9)$ [46]. This procedure was repeated for baseline anxiety (BAI-score). The cut-off for clinically relevant anxiety is set at 16, and therefore we classified women with BAI $\geq 16$ as "highly anxious" $(n=8)$, and women with BAI below 16 as "mildly anxious" $(n=14)$ [47]. One woman had missing data on baseline depression and anxiety and was excluded from the analysis. We took into account allocation status, birth weight, HM850 array chip position, child sex, and age as covariates, as identified by PCA. Differentially methylated probes at a nominal significance level set at $p<0.01$, prior to correction for multiple testing, were extracted. We compared differences in mean DNA methylation in groups of children of women with high baseline symptoms and low baseline symptoms using an unpaired Mann-Whitney-Wilcoxon test, both for depression and anxiety. We additionally compared mean beta differences of 16 candidate genes, and the promoter region of the NR3C1 gene between groups of children of women with high baseline symptoms and low baseline symptoms using an unpaired Mann-Whitney-Wilcoxon test, both for depression and anxiety. 


\section{Appendix}

Table 5 Differential mean methylation of candidate genes in buccal cell DNA of children after maternal antenatal CBT or TAU

\begin{tabular}{llll}
\hline Gene & $\Delta B$ & $95 \%$ Cl & $P$ \\
\hline NR3C1 & 0.004 & -0.004 to 0.011 & 0.32 \\
NR3C1 Promoter & 0.002 & -0.010 to 0.011 & 0.65 \\
SLC6A4 & 0.013 & -0.007 to 0.035 & 0.09 \\
OXTR & 0.008 & -4.7 e-05 to 1.6 e-02 & 0.04 \\
NR3C2 & 0.002 & -0.005 to 0.009 & 0.6 \\
MEST & 0.013 & 0.003 to 0.024 & 0.02 \\
MEG3 & 0.012 & 0.00004 to 0.023 & 0.04 \\
IFG2 & 0.005 & -0.014 to 0.028 & 0.65 \\
HSD11B1 & 0.004 & -0.0123 to 0.019 & 0.61 \\
HSD11B2 & 0.003 & -0.003 to 0.010 & 0.29 \\
H19 & 0.019 & 0.003 to 0.041 & 0.03 \\
CRHR1 & 0.013 & -0.0003 to 0.027 \\
CRHR2 & 0.019 & 0.002 to 0.032 & 0.06 \\
CRHRBP & -0.003 & -0.033 to 0.033 \\
CRH & 0.001 & -0.014 to 0.015 & 0.02 \\
BDNF & 0.001 & -0.005 to 0.008 & 0.93 \\
FKBP5 & 0.006 & -0.0003 to 0.0139 & 0.98 \\
\hline AB & &
\end{tabular}

$\triangle B=$ mean $B(T A U)$ - mean $B(C B T)$

$C B T$ cognitive behavioral therapy, TAU treatment as usual

Table 6 Probes in candidate gene analysis showing differential methylation according to intervention at uncorrected $p<0.01$

\begin{tabular}{llllll}
\hline CpG & $p$ & Adjusted $p^{\text {a }}$ & Gene & Gene region & $\Delta \beta$ \\
\hline cg27338480 & 0.002299634 & 0.999997557 & MEST & $5^{\prime}$ UTR & 0.036568643 \\
cg25579735 & 0.004343149 & 0.999997557 & NR3C1 & $5^{\prime}$ UTR & -0.028037036 \\
cg01913022 & 0.0064351 & 0.999997557 & CRHR2 & TSS1500 & 0.068307524 \\
cg03366382 & 0.006909299 & 0.999997557 & INS-IGF2 & TSS1500 & 0.044997291 \\
cg03128167 & 0.009155461 & 0.999997557 & IGF2 & Body & 0.017691809 \\
\hline
\end{tabular}

$\Delta \beta=$ mean $\beta$ (treatment as usual) - mean $\beta$ (cognitive behavioral therapy)

TSS transcription start site, UTR untranslated region

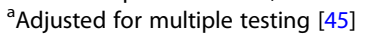

Table 7 Differential methylation according to intervention (promoter-associated NR3C1 probes)

\begin{tabular}{llll}
\hline CpG & $p$ & adjusted $P^{1}$ & $\Delta \beta$ \\
\hline cg26464411 & 0.038765207 & 0.999997557 & 0.016954389 \\
cg07515400 & 0.080810513 & 0.999997557 & -0.006695682 \\
cg10847032 & 0.097881389 & 0.999997557 & 0.002994888 \\
cg06952416 & 0.1418427 & 0.999997557 & 0.022027436 \\
cg06968181 & 0.220252023 & 0.999997557 & 0.007404024 \\
cg18019515 & 0.226633505 & 0.999997557 & 0.002112324 \\
cg04111177 & 0.239037451 & 0.999997557 & -0.002860936 \\
cg18068240 & 0.254658402 & 0.999997557 & 0.002064659 \\
cg21209684 & 0.270282959 & 0.999997557 & 0.002460768
\end{tabular}


Table 7 Differential methylation according to intervention (promoter-associated NR3C1 probes) (Continued)

\begin{tabular}{|c|c|c|c|}
\hline$\overline{\mathrm{CpG}}$ & $p$ & adjusted $P^{\prime}$ & $\Delta \beta$ \\
\hline cg19135245 & 0.272388772 & 0.999997557 & 0.004258499 \\
\hline cg07733851 & 0.279542254 & 0.999997557 & 0.02357243 \\
\hline cg15910486 & 0.292918216 & 0.999997557 & 0.004537478 \\
\hline cg01967637 & 0.338536262 & 0.999997557 & 0.003919932 \\
\hline cg17860381 & 0.357836419 & 0.999997557 & 0.000876506 \\
\hline cg18849621 & 0.379245855 & 0.999997557 & 0.002552033 \\
\hline cg21702128 & 0.406504887 & 0.999997557 & -0.001070247 \\
\hline cg13764763 & 0.454791344 & 0.999997557 & 0.015622476 \\
\hline cg00629244 & 0.503885658 & 0.999997557 & -0.00246556 \\
\hline cg14939152 & 0.504120134 & 0.999997557 & 0.000577132 \\
\hline cg27122725 & 0.529860939 & 0.999997557 & 0.006029979 \\
\hline cg14558428 & 0.531421634 & 0.999997557 & 0.001417758 \\
\hline cg08818984 & 0.551707805 & 0.999997557 & -0.030134797 \\
\hline cg24026230 & 0.564518425 & 0.999997557 & 0.002507375 \\
\hline cg03906910 & 0.630630252 & 0.999997557 & -0.02119966 \\
\hline cg13648501 & 0.652981749 & 0.999997557 & 0.001717513 \\
\hline cg16335926 & 0.740313284 & 0.999997557 & -0.001532178 \\
\hline cg26720913 & 0.743323678 & 0.999997557 & -0.017368038 \\
\hline cg17342132 & 0.818325933 & 0.999997557 & 0.011875955 \\
\hline cg18718518 & 0.88056981 & 0.999997557 & 0.004555236 \\
\hline cg22402730 & 0.908119964 & 0.999997557 & -0.000126521 \\
\hline cg15645634 & 0.908177372 & 0.999997557 & -0.001196809 \\
\hline cg23776787 & 0.933952752 & 0.999997557 & -0.00580295 \\
\hline cg11152298 & 0.951420262 & 0.999997557 & 0.000520728 \\
\hline cg18998365 & 0.961116448 & 0.999997557 & 0.001743816 \\
\hline
\end{tabular}

$\overline{\Delta \beta}=$ mean $\beta$ (treatment as usual) - mean $\beta$ (cognitive behavioral therapy)

TSS transcription start site, UTR untranslated region

${ }^{a}$ Adjusted for multiple testing [45]

Table 8 Top 100 differentially methylated probes according to baseline depression (BDI-II)

\begin{tabular}{|c|c|c|c|c|c|}
\hline CpG & $p$ & Adjusted $p^{\text {a }}$ & Gene & Gene region & $\Delta \beta$ \\
\hline cg01656717 & 5.43E-05 & 0.985858571 & WWP2 & Body & 0.020713379 \\
\hline cg06022376 & 5.62E-05 & 0.985858571 & CACTIN & Body & 0.031934062 \\
\hline cg01120173 & 5.91E-05 & 0.985858571 & ZNF232 & $5^{\prime}$ UTR & -0.032894902 \\
\hline cg24732447 & 8.42E-05 & 0.985858571 & OSTM1 & TSS1500 & -0.040891939 \\
\hline cg17402103 & $9.76 \mathrm{E}-05$ & 0.985858571 & & & 0.044389084 \\
\hline cg10276665 & 0.000102293 & 0.985858571 & PHF2O & $5^{\prime}$ UTR & -0.053135525 \\
\hline $\operatorname{cg} 23119960$ & 0.000108933 & 0.985858571 & TCF12 & TSS1500 & 0.019411015 \\
\hline
\end{tabular}


Table 8 Top 100 differentially methylated probes according to baseline depression (BDI-II) (Continued)

\begin{tabular}{|c|c|c|c|c|c|}
\hline CpG & $p$ & Adjusted $p^{a}$ & Gene & Gene region & $\Delta \beta$ \\
\hline cg07639472 & 0.000110211 & 0.985858571 & GABARAP & TSS200 & 0.009595275 \\
\hline cg14522236 & 0.000112046 & 0.985858571 & & & -0.049713856 \\
\hline cg16561657 & 0.000150143 & 0.985858571 & & & -0.055819652 \\
\hline cg21014120 & 0.00015174 & 0.985858571 & $I C A 1 L$ & TSS200 & -0.006901363 \\
\hline cg02965870 & 0.000158156 & 0.985858571 & NEDD4 & 1stExon & -0.005222348 \\
\hline cg19817882 & 0.000171789 & 0.985858571 & LEFTY1 & Body & 0.034762224 \\
\hline cg02644616 & 0.000173319 & 0.985858571 & & & -0.00792669 \\
\hline cg00369151 & 0.000179443 & 0.985858571 & PIP4K2A & Body & -0.036713932 \\
\hline cg24954665 & 0.000194603 & 0.985858571 & & & -0.018476691 \\
\hline cg08217452 & 0.000200085 & 0.985858571 & & & 0.062010845 \\
\hline cg22796353 & 0.000209579 & 0.985858571 & & & -0.06798597 \\
\hline cg05636467 & 0.000213261 & 0.985858571 & EBF3 & Body & 0.058972943 \\
\hline cg01870580 & 0.000213772 & 0.985858571 & $S G C D$ & Body & -0.033578993 \\
\hline cg04167481 & 0.000227738 & 0.985858571 & $\angle R R C 6$ & Body & -0.02281918 \\
\hline cg07010552 & 0.000233 & 0.985858571 & CHRNB1 & Body & 0.03251269 \\
\hline cg09877950 & 0.000238965 & 0.985858571 & SLC4A10 & Body & -0.050949676 \\
\hline cg08548444 & 0.000241925 & 0.985858571 & & & 0.058594659 \\
\hline cg22870344 & 0.000242958 & 0.985858571 & ATP5B & TSS200 & 0.040824173 \\
\hline cg16692066 & 0.000251174 & 0.985858571 & FNDC7 & Body & -0.027886693 \\
\hline cg03781315 & 0.00025551 & 0.985858571 & AHCY & Body & -0.020798236 \\
\hline cg18303019 & 0.000261834 & 0.985858571 & TXNRD1 & TSS1500 & -0.03100706 \\
\hline cg07381391 & 0.000267381 & 0.985858571 & & & 0.203102371 \\
\hline cg17115402 & 0.000269335 & 0.985858571 & CDR2L & Body & -0.020519014 \\
\hline cg23788051 & 0.000272662 & 0.985858571 & & & 0.034154924 \\
\hline cg15234197 & 0.000277725 & 0.985858571 & & & 0.09308691 \\
\hline cg22521539 & 0.000282937 & 0.985858571 & & & 0.049648454 \\
\hline cg25157095 & 0.000284638 & 0.985858571 & RIPK4 & Body & 0.029861946 \\
\hline cg25464078 & 0.000290016 & 0.985858571 & PPTC7 & Body & 0.041450584 \\
\hline cg24667213 & 0.000295285 & 0.985858571 & & & 0.021353983 \\
\hline cg03716908 & 0.00029717 & 0.985858571 & & & 0.036164552 \\
\hline cg11747082 & 0.000319919 & 0.985858571 & GPR33 & TSS1500 & -0.043309753 \\
\hline cg08446512 & 0.000321548 & 0.985858571 & MIR548Q & Body & -0.057652312 \\
\hline cg10239816 & 0.000321981 & 0.985858571 & GOT1 & TSS200 & 0.010999285 \\
\hline cg24632014 & 0.000329696 & 0.985858571 & LOC100189589 & Body & 0.033737209 \\
\hline cg14255237 & 0.000331265 & 0.985858571 & SARDH & Body & 0.0688885565 \\
\hline cg01874640 & 0.000341932 & 0.985858571 & $H G D$ & ExonBnd & -0.027385445 \\
\hline cg12308055 & 0.000342843 & 0.985858571 & VAC14 & Body & 0.025670901 \\
\hline cg13747435 & 0.000353254 & 0.985858571 & $A K 1$ & Body & 0.02153699 \\
\hline cg26287679 & 0.000353404 & 0.985858571 & MYBL1 & Body & -0.036514738 \\
\hline cg27305222 & 0.000359452 & 0.985858571 & & & -0.040634637 \\
\hline cg09694986 & 0.000364186 & 0.985858571 & SNTB1 & Body & -0.041411009 \\
\hline cg04928577 & 0.000370129 & 0.985858571 & & & -0.069549039 \\
\hline cg02059927 & 0.000376777 & 0.985858571 & & & 0.045567447 \\
\hline cg19553615 & 0.000379462 & 0.985858571 & CRTC3 & Body & 0.021785594 \\
\hline
\end{tabular}


Table 8 Top 100 differentially methylated probes according to baseline depression (BDI-II) (Continued)

\begin{tabular}{|c|c|c|c|c|c|}
\hline CpG & $p$ & Adjusted $p^{\mathrm{a}}$ & Gene & Gene region & $\Delta \beta$ \\
\hline cg06214427 & 0.000382521 & 0.985858571 & MYO1A & Body & -0.027829513 \\
\hline cg14609960 & 0.000388595 & 0.985858571 & PITRM1 & Body & -0.03071115 \\
\hline cg07814876 & 0.000392304 & 0.985858571 & GGPS1 & 5'UTR & 0.02176791 \\
\hline cg03656020 & 0.000394532 & 0.985858571 & VGF & 3'UTR & 0.02323939 \\
\hline cg16977720 & 0.000414373 & 0.985858571 & TRABD2A & Body & -0.015144172 \\
\hline cg111173076 & 0.00041489 & 0.985858571 & ART1 & TSS200 & 0.051579054 \\
\hline cg11407226 & 0.000427414 & 0.985858571 & & & 0.052957159 \\
\hline cg24676514 & 0.000428063 & 0.985858571 & & & 0.007114356 \\
\hline cg24353217 & 0.000430568 & 0.985858571 & MYL2 & Body & 0.048161701 \\
\hline cg13022689 & 0.000438434 & 0.985858571 & & & -0.014053374 \\
\hline cg08013270 & 0.000452709 & 0.985858571 & $E M X 1$ & Body & 0.009802214 \\
\hline cg10486455 & 0.000457554 & 0.985858571 & WDR46 & Body & -0.071572335 \\
\hline cg08824610 & 0.000457605 & 0.985858571 & $S C N 3 B$ & Body & 0.032374425 \\
\hline cg23934072 & 0.00046317 & 0.985858571 & KIF $21 B$ & 3'UTR & 0.072005944 \\
\hline cg08882432 & 0.000492053 & 0.985858571 & CCDC171 & Body & -0.06825542 \\
\hline cg19075081 & 0.000509177 & 0.985858571 & MTSSIL & Body & 0.034977378 \\
\hline cg14940449 & 0.000513204 & 0.985858571 & HGS & TSS200 & -0.004493762 \\
\hline cg27644292 & 0.000535008 & 0.985858571 & SNRPN & $5^{\prime} U T R$ & -0.043063624 \\
\hline cg13277044 & 0.000537047 & 0.985858571 & & & -0.028669058 \\
\hline cg10313065 & 0.000547596 & 0.985858571 & & & 0.027390264 \\
\hline cg27483342 & 0.000549745 & 0.985858571 & & & -0.035483152 \\
\hline cg00167525 & 0.00054993 & 0.985858571 & & & -0.044404069 \\
\hline cg02624701 & 0.000556261 & 0.9858585571 & SLC17A7 & Body & -0.023735747 \\
\hline cg24488506 & 0.000559886 & 0.985858571 & FOSL1 & 1stExon & -0.005249818 \\
\hline cg10894284 & 0.000567688 & 0.985858571 & SPATS2 & Body & -0.05283773 \\
\hline cg00045787 & 0.0005679 & 0.985858571 & SNTB2 & Body & 0.021702408 \\
\hline cg22379574 & 0.000572536 & 0.985858571 & TPT1 & TSS200 & 0.002542434 \\
\hline cg09381162 & 0.000579437 & 0.985858571 & ANXA13 & Body & -0.038107869 \\
\hline cg10562399 & 0.000581216 & 0.985858571 & SNRPG & Body & 0.049683592 \\
\hline cg17422878 & 0.000584164 & 0.985858571 & & & -0.01955572 \\
\hline cg16460816 & 0.000592284 & 0.985858571 & IFT140 & Body & 0.016906513 \\
\hline cg22647874 & 0.000594316 & 0.985858571 & FAM192A & $5^{\prime} U T R$ & -0.01781755 \\
\hline cg04157647 & 0.000594803 & 0.985858571 & CD27-AS1 & Body & -0.068075731 \\
\hline cg14436051 & 0.000595366 & 0.985858571 & PRR26 & Body & -0.018081196 \\
\hline cg11629443 & 0.000598589 & 0.985858571 & TRIM27 & 1stExon & 0.005616034 \\
\hline cg03163982 & 0.00059979 & 0.985858571 & & & -0.008328044 \\
\hline cg11475558 & 0.000600783 & 0.985858571 & TNS1 & Body & 0.028042851 \\
\hline cg18014277 & 0.000608293 & 0.985858571 & APBB1IP & $3^{\prime} U T R$ & -0.016579214 \\
\hline cg02597373 & 0.000619621 & 0.985858571 & UNC13D & Body & 0.05993223 \\
\hline cg23123838 & 0.000622213 & 0.985858571 & MTA1 & TSS200 & 0.023497892 \\
\hline cg03278573 & 0.000627109 & 0.985858571 & $D A P$ & Body & -0.064990789 \\
\hline cg15674937 & 0.000643134 & 0.985858571 & & & 0.073468304 \\
\hline cg01126532 & 0.000643521 & 0.985858571 & & & -0.081499283 \\
\hline cg04736676 & 0.000662804 & 0.9858585571 & MCMЗAP & TSS1500 & 0.012334518 \\
\hline
\end{tabular}


Table 8 Top 100 differentially methylated probes according to baseline depression (BDI-II) (Continued)

\begin{tabular}{llllll}
\hline CpG & $p$ & Adjusted $p^{\text {a }}$ & Gene & Gene region & $\Delta \beta$ \\
\hline cg11240430 & 0.000664374 & 0.985858571 & ANKRD16 & $5^{\prime}$ UTR & 0.017463959 \\
cg00154646 & 0.000664385 & 0.985858571 & & & -0.022644413 \\
cg06434997 & 0.000669569 & 0.985858571 & FBXO5 & $5^{\prime}$ UTR & 0.023162548 \\
cg02030350 & 0.00067758 & 0.985858571 & & Body & -0.030538262 \\
cg13357903 & 0.000693814 & 0.985858571 & MIA3 & TSS1500 & 0.012988536 \\
\hline
\end{tabular}

$\Delta \beta=$ mean $\beta$ (severely depressed) - mean $\beta$ (mildly depressed)

TSS transcription start site, UTR untranslated region

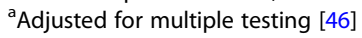

Table 9 Top 100 differentially methylated probes according to baseline anxiety (BAI)

\begin{tabular}{|c|c|c|c|c|c|}
\hline$\overline{\mathrm{CpG}}$ & $p$ & Adjusted $p^{d}$ & Gene & Gene region & $\Delta \beta$ \\
\hline$\overline{c g 06513375}$ & $1.01 \mathrm{E}-06$ & 0.77590274 & ZNF251 & Body & -0.106421132 \\
\hline cg19573881 & $5.11 \mathrm{E}-06$ & 0.998778059 & & & 0.083994741 \\
\hline cg00117018 & $1.40 \mathrm{E}-05$ & 0.998778059 & ZNF251 & Body & -0.13038673 \\
\hline cg11602361 & $3.18 \mathrm{E}-05$ & 0.998778059 & FYN & $5^{\prime} U T R$ & -0.045924181 \\
\hline cg21641920 & $3.80 \mathrm{E}-05$ & 0.998778059 & RBM33 & Body & -0.056092107 \\
\hline cg13511253 & $4.12 \mathrm{E}-05$ & 0.998778059 & MAPK4 & $5^{\prime} U T R$ & -0.06921116 \\
\hline cg11674381 & $4.68 \mathrm{E}-05$ & 0.998778059 & & & -0.030888002 \\
\hline cg00115113 & $5.01 \mathrm{E}-05$ & 0.998778059 & LINC00483 & Body & 0.027732238 \\
\hline cg21918548 & $5.84 \mathrm{E}-05$ & 0.998778059 & ZNF251 & Body & -0.100935223 \\
\hline cg01519784 & $5.87 \mathrm{E}-05$ & 0.998778059 & & & -0.025857817 \\
\hline cg07081372 & $6.58 \mathrm{E}-05$ & 0.998778059 & $T M X 1$ & Body & 0.020743268 \\
\hline cg26293081 & 7.19E-05 & 0.998778059 & TNS3 & Body & 0.039738087 \\
\hline cg06626791 & $7.25 \mathrm{E}-05$ & 0.998778059 & CCNE2 & $5^{\prime} \mathrm{UTR}$ & 0.012276869 \\
\hline cg04788249 & $7.26 \mathrm{E}-05$ & 0.998778059 & ATG7 & $5^{\prime} U T R$ & 0.003609404 \\
\hline cg08049441 & 7.76E-05 & 0.998778059 & RPL32P3 & Body & -0.024015531 \\
\hline cg10731606 & 8.45E-05 & 0.998778059 & $A G B L 3$ & TSS200 & 0.031982023 \\
\hline cg023355517 & 0.000117192 & 0.998778059 & IL6 & Body & -0.013920705 \\
\hline cg12379948 & 0.00011944 & 0.998778059 & WNT3 & TSS1500 & 0.007283815 \\
\hline cg13242754 & 0.000127218 & 0.998778059 & C14orf101 & Body & -0.015166989 \\
\hline cg06245967 & 0.000130491 & 0.998778059 & BANP & $5^{\prime} \mathrm{UTR}$ & -0.029761211 \\
\hline cg21643916 & 0.000138817 & 0.998778059 & PRKARIB & Body & -0.013338272 \\
\hline cg22500132 & 0.000147833 & 0.998778059 & MUC1 & TSS200 & 0.00823408 \\
\hline cg24555816 & 0.000150316 & 0.998778059 & & & 0.058918432 \\
\hline cg02893361 & 0.000160529 & 0.998778059 & PIAST & Body & -0.030954487 \\
\hline cg12906188 & 0.000164316 & 0.998778059 & RGS4 & Body & 0.008487123 \\
\hline cg05524951 & 0.000170319 & 0.998778059 & & & -0.012679223 \\
\hline cg14122980 & 0.000170584 & 0.998778059 & PTPRD & $5^{\prime} U T R$ & -0.023320139 \\
\hline cg13449967 & 0.000178787 & 0.998778059 & ATG2A & Body & 0.029533776 \\
\hline cg17231980 & 0.000185655 & 0.998778059 & & & -0.013659095 \\
\hline cg04657000 & 0.000189668 & 0.998778059 & FYN & $5^{\prime} \mathrm{UTR}$ & -0.012205559 \\
\hline cg18612255 & 0.000205249 & 0.998778059 & & & 0.012801625 \\
\hline cg22063222 & 0.000229138 & 0.998778059 & & & -0.010538791 \\
\hline cg23760165 & 0.000231842 & 0.998778059 & FADS2 & TSS1500 & 0.00669263 \\
\hline cg24531534 & 0.000237063 & 0.998778059 & LOXL2 & Body & 0.102423109 \\
\hline cg15745507 & 0.000240352 & 0.998778059 & & & 0.039058624 \\
\hline cg05731717 & 0.000243608 & 0.998778059 & & & -0.038853941 \\
\hline cg16888838 & 0.000245704 & 0.998778059 & KIAA1549 & 3'UTR & -0.021553937 \\
\hline cg17190403 & 0.000249731 & 0.998778059 & C6orf211 & Body & 0.029783554 \\
\hline cg18298090 & 0.000274478 & 0.998778059 & ETV2 & TSS1500 & -0.035320986 \\
\hline
\end{tabular}


Table 9 Top 100 differentially methylated probes according to baseline anxiety (BAI) (Continued)

\begin{tabular}{|c|c|c|c|c|c|}
\hline CpG & $p$ & Adjusted $p^{\mathrm{a}}$ & Gene & Gene region & $\Delta \beta$ \\
\hline cg11341317 & 0.000285303 & 0.998778059 & & & -0.032941327 \\
\hline cg15264808 & 0.000285946 & 0.998778059 & CENPN & $5^{\prime} \mathrm{UTR}$ & 0.012161477 \\
\hline cg21025551 & 0.000290064 & 0.998778059 & ADRBK2 & TSS200 & 0.008238703 \\
\hline cg15872329 & 0.000304128 & 0.998778059 & BLOC1S2 & Body & 0.010747948 \\
\hline cg26594377 & 0.000311806 & 0.998778059 & EFCAB11 & 5'UTR & 0.007818559 \\
\hline cg27191554 & 0.000311819 & 0.998778059 & NOTCH3 & Body & 0.016376385 \\
\hline cg25899954 & 0.000314492 & 0.998778059 & & & -0.015053877 \\
\hline cg09602803 & 0.000326585 & 0.998778059 & & & 0.052616473 \\
\hline cg23462514 & 0.000333695 & 0.998778059 & RNF212 & TSS200 & -0.085842379 \\
\hline cg18193440 & 0.000336288 & 0.998778059 & TAF1L & 1stExon & 0.071586528 \\
\hline cg09398891 & 0.000343573 & 0.998778059 & & & -0.017821675 \\
\hline cg08949296 & 0.000351898 & 0.998778059 & JPH1 & 1stExon & 0.008914397 \\
\hline cg21943599 & 0.000355323 & 0.998778059 & C1orf125 & TSS1500 & -0.012630326 \\
\hline cg04322378 & 0.000356074 & 0.998778059 & LINC01258 & TSS200 & 0.036276539 \\
\hline cg13921204 & 0.000358982 & 0.998778059 & SEC61A2 & TSS200 & 0.004130793 \\
\hline cg07346187 & 0.000360053 & 0.998778059 & ZC3H12D & Body & 0.008900888 \\
\hline cg11832804 & 0.000361177 & 0.998778059 & TERT & Body & -0.006660909 \\
\hline cg04899629 & 0.00036328 & 0.998778059 & LOR2C3 & TSS1500 & -0.067707778 \\
\hline cg01985858 & 0.000364399 & 0.998778059 & $O B F C 2 B$ & TSS1500 & 0.012234912 \\
\hline cg03851648 & 0.000366413 & 0.998778059 & PHC2 & Body & -0.103038845 \\
\hline cg11102724 & 0.000382353 & 0.998778059 & & & 0.200746665 \\
\hline cg18570658 & 0.000387535 & 0.998778059 & COLAA2 & Body & -0.06295432 \\
\hline cg24942330 & 0.000389195 & 0.998778059 & ASAH1 & TSS1500 & 0.005198328 \\
\hline cg07571142 & 0.00039639 & 0.998778059 & C10orf99 & 3'UTR & -0.022383608 \\
\hline cg14405643 & 0.000402335 & 0.998778059 & IER5L & 3'UTR & 0.026828829 \\
\hline cg13147522 & 0.000402551 & 0.998778059 & SAPS3 & TSS200 & 0.011988911 \\
\hline cg15417944 & 0.000405638 & 0.998778059 & RBM44 & $5^{\prime} U T R$ & -0.03261725 \\
\hline cg00616952 & 0.000409576 & 0.998778059 & SIPATL3 & Body & -0.019003771 \\
\hline cg23166923 & 0.000410512 & 0.998778059 & PMPCA & 1stExon & 0.008004775 \\
\hline cg13297582 & 0.000411378 & 0.998778059 & LDLRAD4 & $5^{\prime} U T R$ & -0.092481987 \\
\hline cg00962271 & 0.000413861 & 0.998778059 & & & -0.042309368 \\
\hline cg11640106 & 0.000416865 & 0.998778059 & LOC101929194 & Body & -0.016168103 \\
\hline cg06981781 & 0.000418137 & 0.998778059 & $E G F$ & Body & -0.011108508 \\
\hline cg24146773 & 0.000418853 & 0.998778059 & $S H 3 B G R$ & 1stExon & -0.083744695 \\
\hline cg23579746 & 0.000438092 & 0.998778059 & FCRLB & TSS1500 & -0.026251069 \\
\hline cg09819772 & 0.000438692 & 0.998778059 & & & -0.019080858 \\
\hline cg06630983 & 0.000440009 & 0.998778059 & PPM1F & Body & -0.013620731 \\
\hline cg09207053 & 0.000444686 & 0.998778059 & PCDHGA11 & TSS200 & 0.021510517 \\
\hline cg11833983 & 0.000447858 & 0.998778059 & KANSL2 & Body & -0.020712784 \\
\hline cg05675803 & 0.000455891 & 0.998778059 & C6orf52 & Body & 0.006716337 \\
\hline cg03265692 & 0.000455941 & 0.998778059 & ATAD1 & TSS1500 & 0.010548663 \\
\hline cg11463903 & 0.000458655 & 0.998778059 & ING5 & TSS1500 & 0.015381351 \\
\hline cg03211481 & 0.00046527 & 0.998778059 & DNAJC1 & Body & -0.022278955 \\
\hline cg17714799 & 0.000472182 & 0.998778059 & CASP6 & TSS1500 & 0.018907097 \\
\hline cg20034712 & 0.000482406 & 0.998778059 & ZNF836 & TSS1500 & -0.060359087 \\
\hline cg11554391 & 0.000485943 & 0.998778059 & AHRR & Body & 0.014764295 \\
\hline cg06166863 & 0.000490293 & 0.998778059 & $P N N$ & TSS200 & 0.007284371 \\
\hline cg26321013 & 0.000491445 & 0.998778059 & WIPF2 & 1stExon & 0.018566869 \\
\hline cg16261619 & 0.000495054 & 0.998778059 & $Z P B P$ & TSS200 & -0.049720147 \\
\hline
\end{tabular}


Table 9 Top 100 differentially methylated probes according to baseline anxiety (BAI) (Continued)

\begin{tabular}{|c|c|c|c|c|c|}
\hline$\overline{C p G}$ & $p$ & Adjusted $p^{\text {a }}$ & Gene & Gene region & $\Delta \beta$ \\
\hline cg06871884 & 0.000495095 & 0.998778059 & LINC00963 & Body & 0.008107368 \\
\hline cg16333300 & 0.000496236 & 0.998778059 & TECTA & Body & -0.023279226 \\
\hline cg21848211 & 0.000497682 & 0.998778059 & & & -0.019228316 \\
\hline cg16287252 & 0.00050262 & 0.998778059 & GLT1D1 & Body & -0.059937553 \\
\hline cg15568778 & 0.000504593 & 0.998778059 & & & -0.009418856 \\
\hline cg15247039 & 0.000514355 & 0.998778059 & & & -0.026521804 \\
\hline cg04800443 & 0.000518233 & 0.998778059 & & & 0.034208928 \\
\hline cg12937337 & 0.000519654 & 0.998778059 & PTEN & $5^{\prime} \mathrm{UTR}$ & -0.020668502 \\
\hline cg05308125 & 0.000534128 & 0.998778059 & & & -0.017025401 \\
\hline cg13267264 & 0.000538758 & 0.998778059 & PRDM14 & TSS200 & 0.023761421 \\
\hline cg06610641 & 0.000538794 & 0.998778059 & ZNF527 & TSS1500 & 0.019166156 \\
\hline cg16642284 & 0.00053992 & 0.998778059 & FOXI2 & TSS200 & 0.019871733 \\
\hline
\end{tabular}

$\Delta \beta=$ mean $\beta$ (severely anxious) - mean $\beta$ (mildly anxious)

TSS transcription start site, UTR untranslated region

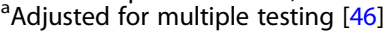

Table 10 Differential methylation of candidate genes according to baseline depression (BDI-II)

\begin{tabular}{|c|c|c|c|}
\hline Gene & $\Delta \beta$ & $95 \% \mathrm{Cl}$ & $p$ \\
\hline$\overline{N R 3 C 1}$ & 0.002 & -0.006 to 0.011 & 0.647 \\
\hline NR3C1 Promoter & 0.006 & -0.005 to 0.020 & 0.2093 \\
\hline SLC6A4 & 0.004 & -0.022 to 0.028 & 0.647 \\
\hline OXTR & 0.003 & -0.009 to 0.010 & 0.5123 \\
\hline NR3C2 & -0.002 & -0.012 to 0.007 & 0.647 \\
\hline MEST & 0.009 & -0.002 to 0.018 & 0.1264 \\
\hline MEG3 & 0.007 & -0.008 to 0.0120 & 0.2921 \\
\hline IFG2 & -0.006 & -0.035 to 0.018 & 0.6005 \\
\hline HSD11B1 & -0.002 & -0.022 to 0.017 & 0.7938 \\
\hline HSD11B2 & 0.004 & -0.005 to 0.009 & 0.2093 \\
\hline H19 & 0.016 & -0.011 to 0.039 & 0.2624 \\
\hline CRHR1 & 0.008 & -0.016 to 0.0221 & 0.3575 \\
\hline CRHR2 & 0.005 & -0.014 to 0.0246 & 0.647 \\
\hline CRHRBP & 0.011 & -0.0262 to 0.0372 & 0.5556 \\
\hline CRH & -0.006 & -0.017 to 0.009 & 0.3237 \\
\hline BDNF & 0.003 & -0.001 to 0.010 & 0.1641 \\
\hline FKBP5 & 0.003 & -0.023 to 0.031 & 0.7414 \\
\hline
\end{tabular}

$\overline{\Delta \beta}=$ mean $\beta$ (severely depressed) - mean $\beta$ (mildly depressed)

Table 11 Probes in candidate gene analysis showing differential methylation according to baseline depression (BDI-II) at uncorrected $p<0.01$

\begin{tabular}{llllll}
\hline CpG & $p$ & Adjusted $p^{\mathrm{a}}$ & Gene & Gene region & $\Delta \beta$ \\
\hline cg17578833 & 0.002812934 & 0.985858571 & CRH & TSS1500 & -0.055448723 \\
cg04137760 & 0.00427371 & 0.985858571 & FKBP5 & 5'UTR & -0.028541521 \\
cg08077673 & 0.007257559 & 0.985858571 & MEST & 5'UTR & 0.008859633 \\
cg07583420 & 0.00759847 & 0.985858571 & IGF2 & Body & 0.00580552 \\
cg13167664 & 0.009158888 & 0.985858571 & IGF2 & Body & 0.003859675 \\
\hline
\end{tabular}

$\overline{\Delta \beta}=$ mean $\beta$ (severely depressed) - mean $\beta$ (mildly depressed)

TSS transcription start site, UTR untranslated region

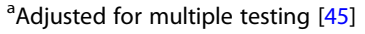


Table 12 Differential methylation of candidate genes according to baseline anxiety (BAI)

\begin{tabular}{|c|c|c|c|}
\hline Gene & $\Delta \beta$ & $95 \% \mathrm{Cl}$ & $p$ \\
\hline NR3C1 & -0.006 & -0.013 to 0.004 & 0.2382 \\
\hline NR3C1 Promoter & 0.008 & -0.001 to 0.019 & 0.0817 \\
\hline SLC6A4 & 0.005 & -0.022 to 0.028 & 0.5699 \\
\hline OXTR & -0.004 & -0.015 to 0.005 & 0.3301 \\
\hline NR3C2 & 0.004 & -0.007 to 0.011 & 0.4411 \\
\hline MEST & 0.013 & 0.001 to 0.023 & 0.01965 \\
\hline MEG3 & 0.012 & -0.0005 to 0.025 & 0.06983 \\
\hline IFG2 & -0.004 & -0.028 to 0.026 & 0.7135 \\
\hline HSD11B1 & 0.009 & -0.008 to 0.027 & 0.2667 \\
\hline HSD11B2 & 0.005 & -0.003 to 0.012 & 0.11 \\
\hline H19 & 0.014 & -0.009 to 0.039 & 0.2382 \\
\hline CRHR1 & 0.003 & -0.015 to 0.021 & 0.6163 \\
\hline CRHR2 & 0.001 & -0.018 to 0.024 & 0.9734 \\
\hline CRHRBP & 0.016 & -0.021 to 0.045 & 0.4411 \\
\hline$C R H$ & -0.007 & -0.019 to 0.006 & 0.402 \\
\hline BDNF & 0.007 & -0.0007 to 0.011 & 0.0817 \\
\hline FKBP5 & 0.005 & -0.003 to 0.014 & 0.145 \\
\hline
\end{tabular}

$\Delta \beta=$ mean $\beta$ (severely anxious) - mean $\beta$ (mildly anxious)

Table 13 Differential methylation according to baseline anxiety (BAI) (promoter-associated NR3C1 probes)

\begin{tabular}{|c|c|c|c|c|}
\hline$\overline{\mathrm{CpG}}$ & $p$ & Adjusted $p^{a}$ & Gene region & $\Delta \beta$ \\
\hline$\overline{c g 07515400}$ & 0.019543236 & 0.998778059 & TSS1500 & 0.008757408 \\
\hline cg22402730 & 0.034941814 & 0.998778059 & TSS1500 & 0.007846464 \\
\hline cg18068240 & 0.074595651 & 0.998778059 & $5^{\prime}$ UTR & 0.003513867 \\
\hline cg00629244 & 0.075603387 & 0.998778059 & TSS200 & 0.005153991 \\
\hline cg21209684 & 0.095644074 & 0.998778059 & 5'UTR & 0.005819462 \\
\hline cg17860381 & 0.172486506 & 0.998778059 & 5'UTR & -0.007857672 \\
\hline cg18849621 & 0.181055644 & 0.998778059 & TSS1500 & 0.007722928 \\
\hline cg26720913 & 0.22868997 & 0.998778059 & 1stExon & 0.071542284 \\
\hline cg16335926 & 0.238092713 & 0.998778059 & TSS1500 & 0.002021547 \\
\hline cg24026230 & 0.24577813 & 0.998778059 & 5'UTR & 0.005938353 \\
\hline cg18019515 & 0.245786808 & 0.998778059 & TSS200 & 0.001549976 \\
\hline cg23776787 & 0.295148027 & 0.998778059 & 1stExon & 0.055157644 \\
\hline cg11152298 & 0.296050346 & 0.998778059 & TSS200 & 0.003074345 \\
\hline cg17342132 & 0.318902496 & 0.998778059 & Body & -0.021285299 \\
\hline cg27122725 & 0.347102162 & 0.998778059 & 5'UTR & 0.035263092 \\
\hline cg10847032 & 0.355174482 & 0.998778059 & TSS1500 & -0.000186142 \\
\hline cg21702128 & 0.358888726 & 0.998778059 & TSS1500 & 0.003153478 \\
\hline cg26464411 & 0.373131972 & 0.998778059 & TSS1500 & 0.008722328 \\
\hline cg18998365 & 0.436272234 & 0.998778059 & 5'UTR & 0.005641782 \\
\hline cg06968181 & 0.486353571 & 0.998778059 & TSS1500 & 0.004702526 \\
\hline cg03906910 & 0.524841281 & 0.998778059 & 1stExon & 0.051231481 \\
\hline cg14939152 & 0.572528468 & 0.998778059 & 5'UTR & -0.003292981 \\
\hline cg04111177 & 0.59537643 & 0.998778059 & 5'UTR & 0.002463121 \\
\hline
\end{tabular}


Table 13 Differential methylation according to baseline anxiety (BAI) (promoter-associated NR3C1 probes) (Continued)

\begin{tabular}{|c|c|c|c|c|}
\hline$\overline{C p G}$ & $p$ & Adjusted $p^{\text {a }}$ & Gene region & $\Delta B$ \\
\hline cg06952416 & 0.665139695 & 0.998778059 & 5'UTR & 0.036482196 \\
\hline cg08818984 & 0.673915225 & 0.998778059 & 1stExon & 0.043838345 \\
\hline cg13648501 & 0.723256995 & 0.998778059 & 5'UTR & 0.008987005 \\
\hline cg19135245 & 0.779311238 & 0.998778059 & TSS1500 & 0.001611098 \\
\hline cg07733851 & 0.816930585 & 0.998778059 & 5'UTR & 0.029161123 \\
\hline cg15645634 & 0.864608392 & 0.998778059 & 5'UTR & -0.002973062 \\
\hline cg01967637 & 0.911624523 & 0.999388148 & 5'UTR & -0.004461401 \\
\hline cg14558428 & 0.913633924 & 0.999388148 & 5'UTR & 0.000461939 \\
\hline cg18718518 & 0.937744615 & 0.999400864 & TSS1500 & 0.023943315 \\
\hline cg13764763 & 0.939306554 & 0.999410992 & TSS1500 & 0.012472219 \\
\hline cg15910486 & 0.975291537 & 0.999632341 & 5'UTR & -0.003768688 \\
\hline
\end{tabular}

?ß = mean $ß$ (severely anxious) - mean $ß$ (mildly anxious)

TSS transcription start site, UTR untranslated region

${ }^{a}$ Adjusted for multiple testing [45]

Table 14 Probes in candidate gene analysis showing differential methylation according to baseline anxiety (BAI) at uncorrected $p ?<? 0.01$

\begin{tabular}{llllll}
\hline CpG & $p$ & Adjusted $p^{\text {a }}$ & Gene & Gene region & $\Delta B$ \\
\hline cg26880525 & 0.00670039 & 0.998778059 & HSD11B1 & 5'UTR & -0.07833178 \\
cg07704699 & 0.007191379 & 0.998778059 & BDNF & Body & 0.026796044 \\
cg13670288 & 0.007464434 & 0.998778059 & IGF2 & Body & -0.003490477 \\
cg23273257 & 0.009092701 & 0.998778059 & NR3C1 & 3'UTR & -0.014724328 \\
\hline CB & & &
\end{tabular}

? $\beta=$ mean $ß$ (severely anxious) - mean $ß$ (mildly anxious)

TSS transcription start site, UTR untranslated region

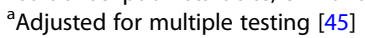

Table 15 Differential methylation according to baseline depression (BDI-II) (promoter-associated NR3C1 probes)

\begin{tabular}{|c|c|c|c|c|}
\hline CpG & $p$ & Adjusted $p^{\text {a }}$ & Gene region & $\Delta \beta$ \\
\hline cg22402730 & 0.09232524 & 0.985858571 & TSS1500 & 0.007914958 \\
\hline cg07515400 & 0.14983598 & 0.985858571 & TSS1500 & 0.00381786 \\
\hline cg18849621 & 0.155838866 & 0.985858571 & TSS1500 & 0.011301146 \\
\hline cg27122725 & 0.191928791 & 0.985858571 & $5^{\prime} U T R$ & 0.04731291 \\
\hline cg19135245 & 0.244476459 & 0.985858571 & TSS1500 & 0.005449225 \\
\hline cg01967637 & 0.254982491 & 0.985858571 & 5'UTR & -0.002502373 \\
\hline cg21702128 & 0.310632555 & 0.985858571 & TSS1500 & 0.003068137 \\
\hline cg06968181 & 0.341577022 & 0.985858571 & TSS1500 & 0.015388067 \\
\hline cg26464411 & 0.354871977 & 0.985858571 & TSS1500 & 0.018949214 \\
\hline cg14558428 & 0.355258299 & 0.985858571 & $5^{\prime} U T R$ & 0.000239683 \\
\hline cg00629244 & 0.377208819 & 0.985858571 & TSS200 & -0.003861647 \\
\hline cg08818984 & 0.399423704 & 0.985858571 & 1stExon & 0.000741573 \\
\hline cg23776787 & 0.447963073 & 0.985858571 & 1stExon & 0.016867225 \\
\hline cg13648501 & 0.469320108 & 0.985858571 & $5^{\prime} U T R$ & 0.016976965 \\
\hline cg03906910 & 0.497810362 & 0.985858571 & 1stExon & 0.010141716 \\
\hline cg18068240 & 0.512386308 & 0.985858571 & $5^{\prime} U T R$ & 0.00411793 \\
\hline cg21209684 & 0.572146062 & 0.985858571 & 5'UTR & 0.00264155 \\
\hline
\end{tabular}


Table 15 Differential methylation according to baseline depression (BDI-II) (promoter-associated NR3C1 probes) (Continued)

\begin{tabular}{|c|c|c|c|c|}
\hline$\overline{\mathrm{CpG}}$ & $p$ & Adjusted $p^{a}$ & Gene region & $\Delta \beta$ \\
\hline cg16335926 & 0.591526062 & 0.985858571 & TSS1500 & 0.003497235 \\
\hline cg04111177 & 0.611636013 & 0.985858571 & $5^{\prime} U T R$ & 0.000989473 \\
\hline cg13764763 & 0.65429048 & 0.985858571 & TSS1500 & 0.008619545 \\
\hline cg14939152 & 0.795018613 & 0.988065713 & $5^{\prime} U T R$ & 0.001196214 \\
\hline cg26720913 & 0.798815567 & 0.988185518 & 1stExon & 0.029770303 \\
\hline cg18998365 & 0.856200047 & 0.991299612 & 5'UTR & 0.016860787 \\
\hline cg07733851 & 0.871021038 & 0.992356236 & $5^{\prime} U T R$ & 0.022062569 \\
\hline cg18718518 & 0.873514581 & 0.992390392 & TSS1500 & 0.015863129 \\
\hline cg06952416 & 0.87457104 & 0.992509068 & $5^{\prime} U T R$ & 0.033670117 \\
\hline cg17860381 & 0.875979533 & 0.992611179 & $5^{\prime} U T R$ & 0.000759159 \\
\hline cg18019515 & 0.916972995 & 0.995093105 & TSS200 & 0.000584247 \\
\hline cg11152298 & 0.925587204 & 0.995541393 & TSS200 & $1.94 \mathrm{E}-05$ \\
\hline cg17342132 & 0.936691926 & 0.996297376 & Body & -0.021376556 \\
\hline cg15645634 & 0.948521192 & 0.997183288 & 5'UTR & -0.001498486 \\
\hline cg24026230 & 0.951640736 & 0.997379305 & 5'UTR & 0.002161506 \\
\hline cg10847032 & 0.979982104 & 0.998978654 & TSS1500 & 0.004273011 \\
\hline cg15910486 & 0.985159251 & 0.999341633 & 5'UTR & 0.003121248 \\
\hline
\end{tabular}

$\Delta \beta=$ mean $\beta$ (severely depressed) - mean $\beta$ (mildly depressed)

TSS transcription start site, UTR untranslated region

${ }^{a}$ Adjusted for multiple testing [45]

\section{Abbreviations}

BAI: Beck Anxiety Inventory; BBB: Beating the Blues before Birth; BDI-II: Beck Depression Inventory-II; CBT: Cognitive behavioral therapy; DSM-

IV: Diagnostic and Statistical Manual of Mental Disorders, 4th Edition; MDS: Multidimensional scaling; PCA: Principal component analysis;

RCT: Randomized controlled trial; TAU: Treatment as usual

\section{Acknowledgements}

We are particularly grateful to all the families who took part in this study.

\section{Funding}

This work was supported by the Brain and Behavior research foundation, under the NARSAD Young Investigator Grant, project 22975, and DynaHealth, under Grant Agreement no 633595, Horizon2020. The funding organizations had no role in the design and conduct of the study; collection, management, and analysis of the data; or preparation, review, and approval of the manuscript.

\section{Availability of data and materials}

The data sets used and/or analyzed during the current study are available from the corresponding author, on reasonable request.

\section{Authors' contributions}

$\mathrm{JM}, \mathrm{AG}$, and $\mathrm{CH}$ contributed to the design and implementation of the original randomized controlled trial. RS and AS assisted in the analysis of DNA methylation data. SdR and LB contributed to the collection of the 5year follow data including the statistical analysis and preparing of the manuscript. TR and $\mathrm{HB}$ aided in interpreting the results and writing of the manuscript. All authors read and approved the final manuscript.

\section{Ethics approval and consent to participate}

The original RCT and the current follow-up study were both approved by the Human Research Ethics Committees of Austin Health, Melbourne, Australia. Trial Registration of the original RCT: ACTRN12607000397415. Registered on 2 August 2007, https://www.anzctr.org.au/Trial/Registration/TrialReview.aspx?id=82169. Informed consent was given by one of the children's parents at the outset of the study.

\section{Consent for publication}

Not applicable.

\section{Competing interests}

The authors declare that they have no competing interests.

\section{Publisher's Note}

Springer Nature remains neutral with regard to jurisdictional claims in published maps and institutional affiliations.

\section{Author details}

${ }^{1}$ Department of Obstetrics and Gynecology, Amsterdam UMC, location AMC, Meibergdreef 9, Amsterdam 1105 AZ, The Netherlands. ${ }^{2}$ Department of Clinical Epidemiology, Biostatistics and Bioinformatics, Amsterdam UMC, location AMC, Meibergdreef 9, Amsterdam 1105 AZ, The Netherlands. ${ }^{3}$ Austin Health, Parent-Infant Research Institute, 300 Waterdale Road, Heidelberg West, VIC 3081, Australia. ${ }^{4}$ Melbourne School of Psychological Sciences, University of Melbourne, Parkville, VIC 3010, Australia. ${ }^{5}$ Murdoch Children's Research Institute_-Cancer and Disease Epigenetics, Royal Children's Hospital, Flemington Road, Parkville, Melbourne, VIC 3052, Australia. ${ }^{6}$ Department of General Practice, University of Groningen, Hanzeplein 1, 9713 GZ Groningen, The Netherlands.

Received: 28 June 2018 Accepted: 14 January 2019

Published online: 04 February 2019

References

1. Bennett HA, Einarson A, Taddio A, et al. Prevalence of depression during pregnancy: systematic review. Obstet Gynecol. 2004;103:698-709.

2. Huizink AC, Robles de Medina PG, Mulder EJH, et al. Stress during pregnancy is associated with developmental outcome in infancy. J Child Psychol Psychiatry. 2003;44:810-8.

3. Hay DF, Pawlby S, Waters CS, et al. Mothers' antenatal depression and their children's antisocial outcomes. Child Dev. 2010;81:149-65.

4. Gerardin P, Wendland J, Bodeau N, et al. Depression during pregnancy. J Clin Psychiatry. 2011;72:378-87. 
5. Korhonen M, Luoma I, Salmelin R, et al. A longitudinal study of maternal prenatal, postnatal and concurrent depressive symptoms and adolescent well-being. J Affect Disord. 2012;136:680-92.

6. Leis JA, Heron J, Stuart EA, et al. Associations between maternal mental health and child emotional and behavioral problems: does prenatal mental health matter? J Abnorm Child Psychol. 2014;42:161-71.

7. Van Batenburg-Eddes T, Brion MJ, Henrichs J, et al. Parental depressive and anxiety symptoms during pregnancy and attention problems in children: a cross-cohort consistency study. J Child Psychol Psychiatry. 2013;54:591-600.

8. Barker ED, Jaffee SR, Uher $\mathrm{R}$, et al. The contribution of prenatal and postnatal maternal anxiety and depression to child maladjustment. Depress Anxiety. 2011;28:696-702

9. Koutra K, Chatzi L, Bagkeris M, et al. Antenatal and postnatal maternal mental health as determinants of infant neurodevelopment at 18 months of age in a mother-child cohort (Rhea Study) in Crete, Greece. Soc Psychiatry Psychiatr Epidemiol. 2013;48:1335-45.

10. Davis EP, Sandman CA. Prenatal psychobiological predictors of anxiety risk in preadolescent children. Psychoneuroendocrinology. 2012;37:1224-33.

11. Pawlby S, Hay DF, Sharp D, et al. Antenatal depression predicts depression in adolescent offspring: prospective longitudinal community-based study. J Affect Disord. 2009;113:236-43

12. Pearson RM, Evans J, Kounali D, et al. Maternal depression during pregnancy and the postnatal period. JAMA Psychiatry. 2013;70:1312.

13. Saffery R. Epigenetic change as the major mediator of fetal programming in humans: are we there yet? Ann Nutr Metab. 2014;64:203-7.

14. Novakovic B, Saffery R. The importance of the intrauterine environment in shaping the human neonatal epigenome. Epigenomics. 2013;5:1-4.

15. Murphy TM, Mill J, Dick K, et al. Epigenetics in health and disease: heralding the EWAS era. Lancet (London, England). 2014;383:1952-4.

16. Schroeder JW, Conneely KN, Cubells JF, et al. Neonatal DNA methylation patterns associate with gestational age. Epigenetics. 2011;6:1498-504.

17. Gudsnuk K, Champagne FA. Epigenetic influence of stress and the social environment. ILAR J. 2012;53:279-88.

18. Mueller BR, Bale TL. Sex-specific programming of offspring emotionality after stress early in pregnancy. J Neurosci. 2008;28:9055-65.

19. Drake AJ. Intergenerational consequences of fetal programming by in utero exposure to glucocorticoids in rats. AJP Regul Integr Comp Physiol. 2004; 288:R34-8.

20. Ryan J, Mansell T, Fransquet P, et al. Does maternal mental well-being in pregnancy impact the early human epigenome? Epigenomics. 2017:9:313-32.

21. Oberlander TF, Weinberg J, Papsdorf $M$, et al. Prenatal exposure to maternal depression, neonatal methylation of human glucocorticoid receptor gene (NR3C1) and infant cortisol stress responses. Epigenetics. 2008;3:97-106.

22. Joubert BR, Felix JF, Yousefi P, et al. DNA methylation in newborns and maternal smoking in pregnancy: genome-wide consortium meta-analysis. Am J Hum Genet. 2016:98:680-96.

23. Van Lieshout RJ, Krzeczkowski JE. Just DO (HaD) It! Testing the clinical potential of the DOHaD hypothesis to prevent mental disorders using experimental study designs. J Dev Orig Health Dis. 2016;7:565-73.

24. Milgrom J, Holt C, Holt CJ, et al. Feasibility study and pilot randomised trial of an antenatal depression treatment with infant follow-up. Arch Womens Ment Health. 2015;18:717-30.

25. Glad CAM, Andersson-Assarsson JC, Berglund P, et al. Reduced DNA methylation and psychopathology following endogenous hypercortisolism—a genome-wide study. Nat Publ Gr. 2017; https://doi.org/ 10.1038/srep44445. Epub ahead of print

26. Radtke K, Schauer M, Gunter H, et al. Epigenetic modifications of the glucocorticoid receptor gene are associated with the vulnerability to psychopathology in childhood maltreatment. Transl Psychiatry. 2015;5 https://doi.org/10.1038/tp.2015.63. Epub ahead of print

27. Deave T, Heron J, Evans J, et al. The impact of maternal depression in pregnancy on early child development. BJOG An Int J Obstet Gynaecol. 2008;115:1043-51.

28. Field T, Diego M, Hernandez-Reif M. Prenatal depression effects on the fetus and newborn: a review. Infant Behav Dev. 2006;29:445-55.

29. Palma-Gudiel H, Córdova-Palomera A, Eixarch E, et al. Maternal psychosocial stress during pregnancy alters the epigenetic signature of the glucocorticoid receptor gene promoter in their offspring: a meta-analysis. Epigenetics. 2015;10:893-902.

30. Radtke KM, Ruf M, Gunter HM, et al. Transgenerational impact of intimate partner violence on methylation in the promoter of the glucocorticoid receptor. Transl Psychiatry. 2011;1:e21.

31. Tobi EW, Slieker RC, Stein AD, et al. Early gestation as the critical timewindow for changes in the prenatal environment to affect the adult human blood methylome. Int J Epidemiol. 2015;44:1211-23.

32. Mulligan CJ, D'Errico NC, Stees J, et al. Methylation changes at NR3C1 in newborns associate with maternal prenatal stress exposure and newborn birth weight. Epigenetics. 2012;7:853-7.

33. Groenwold RHH, Moons KGM, Vandenbroucke JP. Randomized trials with missing outcome data: how to analyze and what to report. CMAJ. 2014;186: 1153-7.

34. Dumville JC, Torgerson DJ, Hewitt CE. Reporting attrition in randomised controlled trials. BMJ. 2006;332:969-71.

35. Houseman E, Accomando WP, Koestler DC, et al. DNA methylation arrays as surrogate measures of cell mixture distribution. BMC Bioinformatics. 2012;13:86.

36. Langie SAS, Moisse M, Declerck K, et al. Salivary DNA Methylation profiling: aspects to consider for biomarker identification. Basic Clin Pharmacol Toxicol. 2017:121:93-101.

37. van der Knaap LJ, Riese H, Hudziak JJ, et al. Glucocorticoid receptor gene (NR3C1) methylation following stressful events between birth and adolescence. The TRAILS study. Transl Psychiatry. 2014;4:e381.

38. Rubertsson C, Börjesson K, Berglund A, et al. The Swedish validation of Edinburgh Postnatal Depression Scale (EPDS) during pregnancy. Nord J Psychiatry. 2011;65:414-8.

39. First MB, Spitzer RL, Gibbon M. Structured clinical interview for DSM-IV axis I disorders, patient edition (SCID-I/P, version 2.0). Washington: American Psychiatric Press; 1996.

40. Beck AT, Ward $\mathrm{CH}$, Mendelson $\mathrm{M}$, et al. An inventory for measuring depression. Arch Gen Psychiatry. 1961;4:561-71.

41. Beck AT, Epstein N, Brown G, et al. An inventory for measuring clinical anxiety: psychometric properties. J Consult Clin Psychol. 1988:56:893-7.

42. Wechsler D. The Wechsler Preschool and Primary Scale of Intelligence, 3rd edition. San Antonio: TX Psychol Corp; 2002

43. Maksimovic J, Gordon L, Oshlack A. SWAN: subset-quantile within array normalization for Illumina Infinium HumanMethylation450 BeadChips. Genome Biol. 2012;13:R44

44. Pidsley R, Zotenko E, Peters TJ, et al. Critical evaluation of the Illumina MethylationEPIC BeadChip microarray for whole-genome DNA methylation profiling. Genome Biol. 2016;17:208.

45. Benjamini $Y$, Hochberg $Y$. Controlling the false discovery rate : a practical and powerful approach to multiple testing. J R Stat Soc B. 1995;57:289-300.

46. Beck AT, Steer RA, Brown GK. BDI-II manual. San Antonio: The Psychological Corporation; 1996.

47. Beck AT, Steer RA. Manual for the Beck anxiety inventory; 1990 .
Ready to submit your research? Choose BMC and benefit from:

- fast, convenient online submission

- thorough peer review by experienced researchers in your field

- rapid publication on acceptance

- support for research data, including large and complex data types

- gold Open Access which fosters wider collaboration and increased citations

- maximum visibility for your research: over $100 \mathrm{M}$ website views per year

At $\mathrm{BMC}$, research is always in progress.

Learn more biomedcentral.com/submissions 